NBER WORKING PAPER SERIES

\title{
WHY HAVE COLLEGE COMPLETION RATES DECLINED? AN ANALYSIS OF CHANGING STUDENT PREPARATION AND COLLEGIATE RESOURCES
}

\author{
John Bound \\ Michael Lovenheim \\ Sarah Turner \\ Working Paper 15566 \\ http://www.nber.org/papers/w15566
}

\author{
NATIONAL BUREAU OF ECONOMIC RESEARCH \\ 1050 Massachusetts Avenue \\ Cambridge, MA 02138 \\ December 2009
}

We would like to thank Paul Courant, Arline Geronimus, Harry Holzer, Caroline Hoxby, Tom Kane, and Jeff Smith for comments on an earlier draft of this paper, and we are grateful to Charlie Brown, John DiNardo, Justin McCrary and Kevin Stange for helpful discussions. We also thank Jesse Gregory and Andrew Winerman for providing helpful research support. We have benefited from comments of seminar participants at NBER, the Society of Labor Economics, the Harris School of Public Policy, the Brookings Institution, Stanford University and the University of Michigan. We would like to acknowledge funding during various stages of this project from the National Science Foundation [SES 1320-0351575], National Institute of Child Health and Human Development [T32 HD007339], the Andrew W. Mellon Foundation, and the Searle Freedom Trust. Much of this work was completed while Bound was a fellow at the Center For Advanced Study in the Behavioral Sciences and Lovenheim was a fellow at the Stanford Institute for Economic Policy Research. The views expressed herein are those of the author(s) and do not necessarily reflect the views of the National Bureau of Economic Research.

NBER working papers are circulated for discussion and comment purposes. They have not been peerreviewed or been subject to the review by the NBER Board of Directors that accompanies official NBER publications.

(C) 2009 by John Bound, Michael Lovenheim, and Sarah Turner. All rights reserved. Short sections of text, not to exceed two paragraphs, may be quoted without explicit permission provided that full credit, including $\odot$ notice, is given to the source. 
Why Have College Completion Rates Declined? An Analysis of Changing Student Preparation and Collegiate Resources

John Bound, Michael Lovenheim, and Sarah Turner

NBER Working Paper No. 15566

December 2009

JEL No. I2,I23

\begin{abstract}
Partly as a consequence of the substantial increase in the college wage premium since 1980, a much higher fraction of high school graduates enter college today than they did a quarter century ago. However, the rise in the fraction of high school graduates attending college has not been met by a proportional increase in the fraction who finish. Comparing two cohorts from the high school classes of 1972 and 1992, we show eight-year college completion rates declined nationally, and this decline is most pronounced amongst men beginning college at less-selective public 4-year schools and amongst students starting at community colleges. We decompose the observed changes in completion rates into the component due to changes in the preparedness of entering students and the component due to collegiate characteristics, including type of institution and resources per student. We find that, while both factors play a role, it is the collegiate characteristics that are more important. A central contribution of this analysis is to show the importance of the supply-side of the higher education in explaining changes in college completion.
\end{abstract}

\author{
John Bound \\ Department of Economics \\ University of Michigan \\ Ann Arbor, MI 48109-1220 \\ and NBER \\ jbound@umich.edu \\ Michael Lovenheim \\ Cornell University \\ 103 MVR Hall \\ Ithaca, NY 14853 \\ mf155@cornell.edu
}

\author{
Sarah Turner \\ Department of Economics \\ University of Virginia \\ 249 Ruffner Hall \\ Charlottesville, VA 22903-2495 \\ and NBER \\ sturner@virginia.edu
}




\section{Why Have College Completion Rates Declined? An Analysis of Changing Student Preparation and Collegiate Resources}

Partly as a consequence of the substantial increase in the college wage premium since 1980 a much higher proportion of high school graduates enter college today than did a quarter century ago. However, the rise in the proportion of high school graduates who attend college has not been met by a commensurate increase in the fraction who become college graduates. Among students who enter college, the share of who complete college is lower today than in the 1970s. This trend is illustrated in Figure 1, which shows that among U.S. born 25-year-olds the likelihood of obtaining a bachelor's degree, conditional on some college participation, dropped from over 45 percent in 1970 to under 40 percent in 1990. In this paper, we explore what accounts for this limited expansion in the supply of college educated workers to the labor force, despite the relatively high level of the college wage premium.

We analyze data from the National Longitudinal Study of the High School Class of 1972 (NLS72) and the National Educational Longitudinal Study of 1988 (NELS:88) to compare the class of 1972 and class of 1992 high school cohorts and show eight-year college completion rates declined nationally across these cohorts by 4.6 percentage points, from 50.5 percent to 45.9 percent. These changes were not uniform across different sectors of higher education, however. Students matriculating at lower ranked public universities and community colleges experienced the full decline in completion rates. In contrast, completion rates increased at public universities ranked in the top 50, as well as at private colleges and universities. Despite greater increases in college-going among women, the drop in completion rates has been almost entirely concentrated among men.

One potentially compelling explanation for the observed drop in completion rates is a compositional shift in the preparation of students attending college. Perhaps due to increasing 
returns to a BA degree, more students with weaker preparation are being induced to attend college in more recent cohorts than were in earlier cohorts. The resulting compositional shift could lead to a lower proportion of students who graduate from college, as the more weakly prepared students drop out. If such a change in the composition of college students contributes to the decline in college completion, we would expect completion rates in those sectors likely to draw the more marginal students -- such as two-year colleges and less-selective public schools -to decline the most, exactly as we do.

However, in addition to a compositional shift among the college-bound, increased college enrollment also generated shifts in the kind of colleges students attend and in the resources available within those institutions. We document a marked reduction in institutional resources in the sectors that experienced declining completion rates. Reductions in resources per student at the institutional level may limit course offerings and student support and can lower the rate at which students are able to complete the requirements for a baccalaureate degree. Such institutional level declines in resources per student can be caused either by reductions in state funding or increases in the number of students a college services at a given budget level. In a higher education market dominated by public and non-profit institutions with different levels of selectivity, a given demand shift or reduction in state funding likely will lead to greater stratification of resources across the sectors of higher education. To the extent that institutional resources influence students' likelihood of college success, these changes could contribute to the national and within-sector trends in completion rates we document.

We decompose the observed changes in completion rates into the component due to compositional changes in the preparation of entering students and into the component due to shifts in college characteristics. While both factors play a role, we find school characteristics are 
more important, particularly among four-year schools. This decomposition is complicated substantially by our use of a logit model to handle the binary nature of college completion. We construct counterfactual completion rate measures by simulating what completion rates would be in the NELS:88 sample if the distribution of high school test scores, college student-teacher ratios or initial college type were shifted in a rank-order neutral manner to be identical to the distributions in the NLS72 sample. These simulations allow us to isolate the contribution of each factor to the total observed change in completion rates.

We find that shifts in the preparation of students entering college (as measured by math test scores) account for about one-third of the observed decline in completion rates; decreases in institutional resources (as measured by increases in college student-faculty ratios) account for about one quarter of the observed completion rate decline; and sectoral shifts in where students first attend college account for three quarters of the observed national decline. Together, these factors can explain more than the total reduction in completion rates that have occurred since the 1970s. Other student characteristics, such as parental educational attainment, have shifted in ways that would serve to increase completion rates across surveys.

For students beginning college at a lower-ranked public university, declines in academic preparation were too small to explain more than a trivial portion of the completion rate drop, but increases in student-faculty ratios account for over three quarters of the total observed completion rate reduction. For community college students, conventionally measured academic resources-either expenditures per student or student-faculty ratios-explain little of the completion rate decline, while declines in college preparation account for almost 90 percent of the total drop in completion rates. 
The key finding of this analysis is that the supply-side of higher education plays an important role in explaining changes in student outcomes. The higher education literature has focused on how student preparation for college translates into college success. Our analysis suggests that, at least for changing completion rates, student preparation is only a partial explanation; characteristics of the supply-side of the market have a substantial influence on student success in college.

In Section I of this paper, we describe the data we use and show the changes in completion rates found in the data, both nationally and across sectors of higher education. In Section II, we outline a theoretical framework for understanding why these observed changes have occurred and describe our empirical framework for distinguishing between these potential explanations. In Section III, we present the results from our decomposition analysis, and in Section IV we offer our conclusions.

\section{Data and Descriptive Statistics}

\section{A. Measuring Completion Rates}

The data for our analysis come from NLS72 and NELS:88. We use these datasets rather than larger datasets with more cohorts of observation, such as the U.S. Census, because the NLS72 and NELS:88 contain information on which college each student attended, the timing of attendance, and graduation outcomes that are necessary to accurately measure cohort-specific completion rates. ${ }^{1}$ These surveys draw from nationally representative cohorts of high school and middle school students, respectively, and track the progress of students longitudinally through

\footnotetext{
${ }^{1}$ Note that trends in college completion rates are inherently difficult to calculate. First, prior to the 1990s, most national surveys asked about educational attainment in terms of completed years of schooling, where completing four years of college is only an imperfect proxy for BA degree attainment. Second, distinguishing immigrants from those born in the United States is important in time series analysis as the number of immigrants with at least a college degree has increased dramatically in the last 15 years.
} 
collegiate and early employment experiences. We define the completion rate as the proportion of students who attend college within two years of cohort high school graduation ${ }^{2}$ and obtain a BA within eight years of cohort high school graduation. ${ }^{3}$

\section{B. Trends in College Enrollment and Completion Rates}

The longitudinal surveys show that college enrollment rates and college completion rates have not moved in parallel in recent decades in the United States. Between the two cohorts there was a substantial increase in college participation, which occurred against the background of little appreciable change in high school graduation rates or measured secondary school achievement. $^{4}$

As illustrated in Table 1, the overall participation rate increased from 48.4 percent to 70.7 percent. Although the size of the high school graduation cohort was smaller in 1992 than in 1972, the increased attendance rate led to growth in the number of students attending college, from 1.4 to 1.8 million. By gender, the increase is greater for women, rising from 46.5 percent to 73.5 percent, than it is for men, rising from 50.4 percent to 68.0 percent.

\footnotetext{
${ }^{2}$ Cohort high school graduation is June 1972 for NLS72 respondents and June 1992 for NELS:88 respondents. See the Technical Appendix in Appendix A for detailed discussion of the NLS72 and NELS:88 datasets used in this analysis. Restricting the analysis to those who attend college within two years of cohort high school graduation has little effect on the results. In NLS72, 11.1 percent of college attendees delayed entry by more than two years, and in NELS:88, 8.8 percent delayed entry by more than two years. Changes in the timing of first entry thus cannot explain the shifts over time in completion rates between the two surveys.

${ }^{3}$ Note that there may be some further closure in aggregate college completion rates measured with a longer lag from high school graduation. John Bound, Michael Lovenheim, and Sarah Turner (2007) show that while there has been a substantial elongation of time to degree that has occurred between these two surveys, much of this change is shifts within the eight-year window of observation; the proportion of eventual college degree recipients receiving their degrees within eight years does not appear to have changed appreciably. Using the 2003 National Survey of College Graduates, which allows us to examine year of degree by high school cohort, we find the share of eventual degree recipients finishing within eight years holds nearly constant between 0.83 and 0.85 for the high school classes of 1960 to 1979. Focusing on more recent cohorts (and, hence, observations with more truncation) we find that in the 1972 high school graduating cohort, 92.3 percent of those finishing within twelve years had finished in eight years, with a figure of 92.4 percent for the 1988 cohort.

${ }^{4}$ Tabulations from the October Current Population Survey (CPS) show 81.0 percent of nineteen-year-olds in 1972 had a high school degree and, in 1992, 81.8 percent had a high school diploma. James J. Heckman and Paul A. Lafontaine (Forthcoming) use a variety of data sources and show relatively stable high school graduation rates over the time period of our analysis as well.
} 
To capture the differentiation among collegiate experiences, we split post-secondary institutions into five sectors, which are reflected in Table 1: non-top 50 public four-year schools, top 50 public four-year schools, less selective private four-year schools, highly selective private four-year schools, and community colleges. ${ }^{5}$ Table 1 illustrates that the overall increase in college participation has not been divided evenly among different types of institutions in the U.S. postsecondary market. The largest change over this time has been the 12.5 percentage point increase in the likelihood of starting at a community college; ${ }^{6}$ these shifts were larger for men than for women.

Overall, increases in the rate of college enrollment have been accompanied by decreases in completion rates (Table 2). Similar to the enrollment shifts, these changes were not uniform across sectors: the BA completion rate among those starting at public two-year institutions slipped to 17.6 percent from 20.2 percent. Similarly, the completion rate fell by 4.9 percentage points between the NLS72 and NELS:88 cohorts among students beginning college in public non-top 50 institutions. In contrast, completion rates increased in the top 50 public schools as well as in private schools. The divergence in completion rates by type of institution suggests that national trends fail to record the stratification in outcomes that occurred both within the four-year sector and between the four-year sector and community colleges since the 1970s. The erosion in completion rates within the non-top 50 public sector suggests that the national trends are not

\footnotetext{
${ }^{5}$ We employ the rankings assembled by U.S. News and World Report in 2005 to classify schools into one of the five divisions. The top 50 public schools are all public colleges and universities ranked in the top 50 in that year, and the highly selective private schools are composed of the top 65-ranked private universities and the top 50ranked liberal arts colleges (plus the U.S. Armed Services Academies). These schools are listing in Appendix A. Other metrics, such as resources per student or selectivity in undergraduate admissions, give similar results. While these divisions are admittedly somewhat arbitrary, on the whole they capture the differences across the different types of post-secondary schools. The U.S. News rankings of institutions are highly correlated over time, and there are few changes across the large groupings we use to categorize schools. Thus, our use of the 2005 rankings when we are studying earlier periods will not affect our results.

${ }^{6}$ All references to two-year schools and community colleges refer to public institutions only. We exclude private two-year schools as they often are professional schools with little emphasis on eventual BA completion. In the NLS72 cohort, 1.7 percent attended a private two-year school, and 1.1 percent of the NELS:88 sample attended such an institution.
} 
being driven solely by the enrollment shift to community colleges, where completion rates are lower and many students may not intend ultimately to earn a BA.

While including community college students in our aggregate measure magnifies the total reduction in completion rates, we believe this inclusion is appropriate for two reasons. First, although it is possible that some students enter community colleges for sub-baccalaureate vocational training, the majority (69.9 percent) of community college entrants in the NELS:88 cohort intended to complete a BA. ${ }^{7}$ Secondly, because attendance at a community college provides the important option to continue to the completion of a four-year degree, these students are significant in the determination of cohort college completion rates.

Table 2 also contains completion rate changes across cohorts separately by gender. In general, men's completion rates declined substantially relative to women's, with the rate for males dropping by 8.5 percentage points and the rate for women declining a not statistically significant 0.6 percentage points. Similar trends are apparent across sectors. For men attending public non-top 50 universities and community colleges, completion rates dropped substantially. For women, while completion rates fell slightly in the non-top 50 public and community college sectors, rates rose dramatically in the top 50 public and private sectors.

\section{Measuring Student Attributes}

One of the major advantages of the NLS72 and NELS:88 data is the rich set of background information available about respondents. The student attributes we use throughout this analysis are high school math test percentile, ${ }^{8}$ father's education level, mother's education

\footnotetext{
${ }^{7}$ Note that aspirations for degree completion among community college students who are recent high school graduates are likely to be somewhat higher than measures for the overall population of community college students that includes a high fraction of older and non-traditional students. Our results are broadly consistent with Laanan Santos (2003), who employs the 1996 Freshman Survey from Cooperative Institutional Research Program (CIRP).

${ }^{8}$ The math tests refer to the exams administered by the National Center for Education Statistics (NCES) that were given to all students in the longitudinal surveys in their senior year of high school. Because the tests in
} 
level, real parental income levels, gender, and race. Our analysis uses math test percentiles as our primary indicators of college preparation because, under reasonable assumptions, we are able to compare these measures over time and among students attending different high schools. ${ }^{9}$

Because there has been little change in the overall level of test scores on the nationallyrepresentative National Assessment of Educational Progress (NAEP) over our period of observation, we argue that the academic preparation of high school graduates did not change over our period of observation. Conditional on math test percentiles, we find other tests, such as reading, have no predictive power for completion rates. Decomposition results with the inclusion of reading test percentiles in the analysis are unchanged from those reported below, and we therefore use only math test percentiles for parsimony in the empirical analysis.

Mother's and father's education is split into five levels: less than high school, high school diploma (including a GED), some college, college graduate and any post-collegiate attainment. For the measurement of family income, we are interested in assessing parents' ability to finance college, so the variable of interest is the real income level, not one's place in the income distribution. We align income in the two surveys using the Consumer Price Index (CPI) into 6 comparable income blocks representing responses to categorical questions about parental income.

The NLS72 and NELS:88 datasets contain a significant amount of missing information on test scores, parental education and parental income brought about by item non-response. While a small share of observations is missing all of these variables (in NLS72 and NELS:88,

NLS72 and NELS:88 covered different subject matter, were of different lengths, and were graded on different scales, the scores are not directly comparable across surveys. We therefore assign each respondent a math test percentile, which is his percentile in the entire distribution of test-takers who graduated from high school.

${ }^{9}$ This test score measure is used as a simple proxy for preparedness. Measures of high school performance such as high school GPA and class rank are other commonly used measures of preparation. We have chosen not to include GPA measures because we are concerned about difficulty in comparing this measure across high schools and the presence of grade inflation over time. 
respectively, 0.5 percent and 0.6 percent have no information on any of these variables), a

substantial number of cases are missing either test scores, parental education or parental

income. ${ }^{10}$ We use multiple imputation methods (Donald B. Rubin, 1987) on the sample of all

high school graduates to impute missing values using other observable characteristics of each

individual. ${ }^{11}$ The Technical Appendix (available online) to this paper in Appendix A contains

detailed information on the construction of our data set.

Table 3 presents the changes in background characteristics and academic preparation of college attendees and graduates across the NLS72 and NELS:88 surveys. Notably, there was a sizeable shift in the proportion of students entering college from lower on the high school test score distribution. Average math test percentiles among those enrolling in college dropped from 62.5 to 58.0 across cohorts, and the percent of college attendees from the highest math test quartile dropped from 40.7 to 32.8, while the percent from the lowest math test quartile increased from 11.2 to 15.6 . However, these declines occurred only in the two-year sector; math test percentiles remained constant or increased in all four year sectors across the two surveys. This fact foreshadows a key finding of this paper: that changing student college preparation, as measured by math test percentiles, cannot account for the decline in completion rates in the public non-top 50 sector.

${ }^{10}$ For example, in NLS72, 40.5 percent of those who enroll in college and 40.8 percent of those receiving a BA within eight years of cohort high school graduation are missing information on at least one of these background characteristics. These percents are 42.5 and 37.5, respectively, in NELS:88. Because the data are not missing completely at random, case-wise deletion of observations with missing variables will bias the unconditional sample means of completion rates.

${ }^{11}$ Under the assumption that the data are missing conditionally at random, multiple imputation is a general and statistically valid method for dealing with missing data (Rubin, 1987; Little, 1982). The relative merits of various approaches for dealing with missing data have been widely discussed (e.g. Little and Rubin, 2002; Schafer, 1997). See the Technical Appendix in Appendix A for complete details of the imputation procedure. Because the surveys contain good supplementary predictor variables, such as high school GPA, standardized test scores from earlier survey waves, and parental income reports, we are able to use a great deal of information about each respondent to impute ranges of missing data points. 
Figure 2 shows the likelihood of college entry and college completion for high school graduates, as well as the completion rate conditional on college entry. The figure clearly indicates that the likelihood of attending college rose across the board. In 1972, there were many high school graduates who appear to have been well qualified to attend college but who did not enroll. By 1992, this was a rarer phenomenon. At the same time, the figure makes clear that the greatest enrollment shifts occurred for those that appear less well prepared, and those with relatively low academic achievement were unlikely to complete the BA degree in either cohort. As a result, the average math test percentile actually rises among BA recipients across the two cohorts, from 70.7 to 71.7. In the bottom quartile of the test score distribution, the likelihood of attending college increases from 21.7 percent to 44.0 percent, which is consistent with a larger percentage of less-prepared students attending college in the later cohort in order to take advantage of the rising returns to education. However, among this group, only 5.6 percent in the initial period of observation receive a BA, and this percent falls yet further to 5.0 for the later cohort. Focusing on college attendees, the likelihood of completing a BA declined from 25.8 percent to 11.4 percent across cohorts for those in the bottom quartile of math test scores. The strong link between our measure of pre-collegiate achievement and the likelihood of college completion shown in Figure 2 suggests that changes in the distribution of preparation among college entrants is a potentially important factor in understanding the change in the aggregate college completion rate.

The gender differences in college completion shown in Table 2 correspond to a dramatic decline in the skill gap between men and women across cohorts, as measured by pre-collegiate math test percentiles. Figure 3 presents cumulative distributions of math test percentiles for the full sample of college attendees and separately by college sector. Overall, the distribution of 
math percentiles observed for women shifted towards the distribution observed for men. While this convergence occurred in all sectors, both the male and female distributions shifted upward dramatically in the selective private sector, implying a larger overall upward shift for women due to the pre-existing differences in the NLS72 survey. These distributional shifts can be attributed to the fact that the math skill gap narrowed between men and women over this period and the fact that in the 1970s, many high-skilled women did not attend college (Claudia Goldin, Lawrence F. Katz, and Ilyana Kuziemko, 2006). By the 1990s, this attendance gap had disappeared. However, the fact that more high-skilled women were drawn into higher education across cohorts suggests college preparation can be only a partial explanation for the aggregate completion rate decline shown in the previous section.

The evidence presented in Table 3 and Figures 2 and 3 suggest that reductions in college preparation likely play a limited role in explaining declining college completion rates, particularly for the four-year non-top 50 public sector in which math test percentiles remained constant across cohorts. In addition, shifts in other precollegiate characteristics favor increased college completion. For both college attendees and graduates, Table 3 shows parental education became more favorable. ${ }^{12}$ Echoing the general increase in educational attainment during the post-war period, the proportion of college attendees whose father (mother) had at least a BA increased by 7.8 percentage points (13.5 percentage points) for all college attendees. Such shifts implicitly go in the "wrong direction" to explain the observed changes in completion rates.

\footnotetext{
${ }^{12}$ While parental education tended to increase over the period of observation, it is well-known that the overall likelihood of growing up in a two-parent family declined. For example, Census Bureau tabulations show the proportion of all children living with two parents falling from 83 percent to 73 percent between 1972 and 1992. While we are able to observe family structure in the NELS:88 survey (and the relationship with collegiate outcomes), this variable is not observed for NLS72. Yet because changes in family structure measured in the CPS among those enrolling in college are quite modest, we conclude that changes in this variable cannot be a primary determinant of changes in completion rates.
} 


\section{Trends in Institutional Resources}

There has been a sizeable shift in college-level resources that has occurred differentially across sectors of higher education. Overall, resources per student either increased or held constant on a number of widely reported scales from the 1970s to the 1990s. To illustrate, constant dollar current expenditures per student at public colleges and universities have risen from $\$ 14,610$ in $1970-71$, to $\$ 17,606$ in $1990-91$, to $\$ 22,559$ in 2000 -01 (Thomas D. Snyder, Alexandra G. Tan, and Charlene M. Hoffman, 2006, Table 339). Such measures miss two fundamental changes occurring over this period: first, the stratification in resources across institutions increased, with large increases in resources at private and selective public institutions combined with stagnation and decline in resources at other institutions; ${ }^{13}$ and secondly, changes in spending per student combine changes in the price of educational inputs with changes in quantities. ${ }^{14}$

Table 4 presents the distribution of student-faculty ratios by type of institution, calculated from the HEGIS/IPEDS institutional surveys, along with the median level of instructional expenditures per student. While there were large cross-sector differences that existed in 1972, student-faculty ratios became much larger in the non-top 50 public and two-year sectors and increased less significantly or decreased in the private sector and the top 50 public universities over time. For example, while mean student-faculty ratios fell among the top 50 public sector institutions and the highly selective private institutions, they increased by 14 percent in the

\footnotetext{
${ }^{13}$ A number of other researchers have noted the rise in stratification among institutions in recent decades, with particular attention to the divergence between the public sector and the private sector. Thomas J. Kane, Peter R. Orszag and David L. Gunter (2003) note that the combination of declines in state appropriations and political restrictions on tuition increases led to declines in spending per student at public schools relative to private schools, with the ratio of per student funding dropping from about 70 percent in the mid-1970s to about 58 percent in the mid-1990s. Caroline M. Hoxby (Forthcoming) shows that tuition, subsidies and student quality have stratified dramatically across the 1962 quality spectrum of higher education since that time.

${ }^{14}$ While the employment of a price index specific to the overall mix of inputs employed by colleges and universities (e.g., Higher Education Price Index) reduces the constant dollar growth in expenditures, it is likely faculty salaries and the cost of laboratory equipment at research universities have outpaced this general index.
} 
public non-top 50 sector and by 40 percent in community colleges. Even larger relative increases occurred at below-median institutions. While median real instructional expenditures decreased overall, from $\$ 4,716$ per student to $\$ 4,339$ per student, this aggregate comprises an increase in resources within selective private universities and decreases at community colleges and public universities outside the top tier. Our analysis below focuses on student-faculty ratios as our measure of institutional resources because we believe that they more accurately reflect resources available to students.

It is natural to ask whether the shift toward attendance at community colleges across cohorts reflects adjustment to changing student characteristics or plausibly exogenous changes in the supply-side of the market. We estimate a multinomial logit model of initial school choice on student background characteristics from NELS:88 and then predict initial sector of attendance using these coefficients and the NLS72 data. These predictions represent the counterfactual distribution of students by institution that would have been expected to occur had the later cohort had the same distribution of observable characteristics as the earlier cohort. Our calculations show changes in student observables explain virtually none of the observed cross-cohort shifts in initial school choice. These simulations suggest changes in the supply-side of the market are important in explaining shifts in where students entered the postsecondary system. Because the two-year sector is relatively elastic in supply response (Bound and Turner, 2007), enrollment demand is most likely to be accommodated at these institutions in periods of expansion.

\section{Empirical Strategy to Decompose the Changes in Completion Rates}

The theoretical underpinnings of our empirical analysis are based on predicted student responses to increases in the returns to a college education, which is one of the dominant trends 
in higher education over the past 30 years. As the returns to a college degree increase, more students are induced to attend college and more of the students who already would have attended college will complete in order to realize the return on their investment. Thus, holding student skills and college quality constant, an increase in the return to college should increase the likelihood of college completion. However, many of the newer students induced to attend college will be less prepared for collegiate success and these marginal students are likely to have a lower probability of completing college than the inframarginal students. These two shifts have opposite effects on completion rates. Which effect will dominate is an empirical question.

Changes in the supply-side of the market, including which sector of higher education college students attend and the resources per student at these colleges, also can affect collegiate attainment. Increasing college attendance itself may further change the resources to which students are exposed while enrolled. Because the higher education market is dominated by public colleges and universities with budget systems that do not adjust fully to demand increases, higher enrollment leads to a reduction in resources per student, with increased scarcity (selectivity) at those institutions that are the most resource-intensive. Nevertheless, even in the presence of reductions in expected resources per student and a reduced likelihood of attending a top-tier institution resulting from a general demand increase for postsecondary education, uncertainty about actual collegiate resources and likelihood of collegiate success can induce students to enroll in an institution with low resources in order to take advantage of high potential returns (i.e., the option value of schooling ${ }^{15}$ ), only to find out that it is difficult to enroll in required classes and that student support services are limited. Declining student resources over time,

\footnotetext{
${ }^{15}$ In addition to recent treatments of the option value in educational investments (e.g., Heckman and Salvador Navarro (2007), Heckman, Lance J. Lochner and Petra E. Todd (2008), Joseph G. Altonji (1993) and Kevin Stange (2008)), a long series of papers, including Burton A. Weisbrod (1962), in the economics literature acknowledge the importance of the option component of educational investments.
} 
particularly in non-top 50 public universities and community colleges, therefore may play a role in explaining the trends in completion rates we observe in the data.

It is important to emphasize that the demand-side and supply-side explanations described above are not mutually exclusive: less-prepared students sort into the most elastic sectors of higher education, which tend to have the fewest resources. In essence, increased demand for college crowds more students (and more less-prepared students) into community colleges and non-top 50 public universities. Demand increases therefore not only lower the resources per student at these institutions, but cause higher dispersion in resources across the sectors of higher education. The implication of this sorting process is that one should observe the largest declines in completion rates in the most elastic sectors, which is indeed the pattern prevalent in the data.

Because changes in student preparation for college and institutional resources are closely linked through the returns to education and the college admissions system, it is not clear from examining the aggregate data how important individual demand-side or supply-side factors are in explaining changing college completion rates. Our empirical objective in the paper is to disentangle the individual contribution of these factors; we seek to decompose the total change into the part due to shifts in student preparation and the part due to college-level factors. In order to isolate the independent effects of student preparation and college resource changes on changes in completion rates, we run logit models of the probability of completion on student math test percentiles, collegiate student-faculty ratios, student demographic characteristics and initial college-type fixed effects.

The central difficulty in undertaking the proposed decompositions stems from the nonlinearity of the logistic function. In a linear framework, the decomposition is straightforward: the change in the mean of an explanatory variable multiplied by the estimated coefficient on that 
variable from the outcome regression represents the partial effect that the change in this characteristic has on the total change in the outcome. For example, if one estimated our completion equation using a linear probability model, the effect of changes in any observable $\left(x_{j}\right)$ on the observed change in completion rates could be calculated simply by multiplying the estimated partial effect of $x_{j}$ on completion rates by the change in the mean of $x_{j}$ across surveys.

In a non-linear model, such as a logit, the exercise becomes both conceptually and computationally more difficult because the estimated partial effects vary across the sample. For individuals who are estimated to be either very likely or very unlikely to finish college, changes in $x_{j}$ will have little effect on the changes in the probability of completion. On the other hand, for individuals whom our estimates suggest have a roughly fifty percent chance of finishing college, changes in the observables will have a potentially large effect on the estimated likelihood of college completion. We therefore cannot simply multiply the estimated marginal effect by the difference in means across samples, as the simulated effects of a discrete change in an explanatory variable will depend on what part of the distribution shifted.

Simulating the change in all of the explanatory variables is straightforward; one method is to use estimates from the NELS:88 data to simulate predicted probabilities using the NLS72 data. The difference between the average of these predicted probabilities and the sample fraction that complete college in the NELS:88 data represents an estimate of the effect of compositional changes of all our observables on completion rates. ${ }^{16}$ Note that non-parametric reweighting using the characteristics of students from the NLS72 survey would produce a nearly identical counterfactual completion rate in which the proportion of students with a given characteristic or

\footnotetext{
${ }^{16}$ Starting with estimates of completion generated from the NLS72 baseline produces parallel results.
} 
a given set of characteristics has not changed between the two surveys. ${ }^{17}$ We employ the former method to simulate the effect of a change in all observables on the change in completion rates, but we obtain similar results when we use non-parametric reweighting techniques.

Beyond measuring the total effect of compositional changes, we want to estimate the effect of changes in individual explanatory variables. To this end, we want to predict the completion rate under the counterfactual assumption that test scores followed the distribution of the early cohort while other covariates maintained the later distribution. Sergio Firpo, Fortin, and Lemieux (2007) note the general challenge in dividing the composition effect into the role of each covariate for distributional measures beyond the mean. Focused on distributional measures in the context of the structure of earnings, the authors develop a general method for doing this decomposition using influence functions. In our context of a dichotomous dependent variable, we pursue an approach focused on estimation of the counterfactual for any variable using a matching estimator.

It will be easiest to explain our approach in the context of a specific example. We are interested in using our estimates to simulate the effect that a change in the distribution of college preparation, proxied by the change in math test percentiles among college goers, had on completion rates. To do this simulation, we construct counterfactual variables by assigning to each observation in the NELS:88 sample a math test percentile from the NLS72 sample that corresponds to the same relative rank: the individual with the highest percentile score in NELS:88 is assigned the top value from NLS72, the second-ranked in each survey are matched, and so on (with ties broken randomly). Done without replacement, this matching algorithm

\footnotetext{
${ }^{17}$ Re-weighting estimators have a long history in statistics dating back at least to the work of Daniel G. Horvitz and David J. Thompson (1952) and have become increasingly popular in economics (see, for example, John DiNardo, Nicole M. Fortin and Thomas Lemieux, 1996; Heckman, Hidehiko Ichimura, and Todd, 1997 and 1998 ; and Robert Barsky, Bound, Kerwin Charles and Joseph Lupton, 2002).
} 
reproduces the NLS72 math test percentile distribution in the NELS:88 sample, holding relative ranking constant across the surveys. This method ensures we are not randomly assigning high (low) math test values to individuals who would be predicted to have low (high) math test scores based on the other characteristics we observe about respondents. We then use the parameters from our estimated logit model of completion on the NELS:88 sample and calculate counterfactual completion rates in which math tests scores have changed in a rank-neutral manner but other characteristic have remained the same. While the above example focuses on math test distribution changes, it is straightforward to use this methodology to generate counterfactual completion rates for a shift in any of our independent variables. ${ }^{18}$

The validity of our counterfactual calculations (e.g., what would the college completion rate for those attending college in the 1990s have been had they been as academically prepared for college as those who attended in the 1970s?) depends crucially on the cross-sectional association between background characteristics and college outcomes reflecting a causal relationship not seriously influenced by confounding factors. ${ }^{19}$ For example, we simulate completion rates under a counterfactual distribution of test scores. For this simulation to accurately represent the counterfactual, it must be the case that the cross-sectional relationship between test scores and the likelihood of college completion reflects the impact of pre-collegiate academic preparation on this outcome. Regardless of whether the simulation calculation produces the "true” counterfactual, the results present a clear accounting framework for assessing the descriptive impact of the change in the composition of students and the institutions they attend on collegiate attainment.

\footnotetext{
${ }^{18}$ When we construct counterfactual completion rates for student-faculty ratios, we do not assign a counterfactual value to NELS:88 respondents with missing student-faculty ratios. This methodology allows us to match student-faculty ratio distributions among those with observed student-faculty ratios in both surveys.

${ }^{19}$ Firpo, Fortin, and Lemieux (2007) make the same point.
} 
A related identification issue associated with our decomposition analysis is that math test percentiles and student-faculty ratios must be accurate proxies of student preparation and institutional resources, respectively. A particular concern is that both test scores and studentfaculty measures are imperfect proxies for the constructs in which we are interested. While the general effect of such errors in measurement is to bias downward the effects estimated in the simulations, we are unable to assess the relative adequacy of these measures. Nevertheless, in the case where the distribution of test scores does not change across cohorts while the distribution of resources changes markedly, we can be confident that changes in preparation are not central in the explanation. Moreover, within sector, the correlation between test scores and student-faculty measures is low. This supports the interpretation that institutional resource effects are not simply reflecting the effects of unmeasured "ability" generated by the correlation with the residual part of academic preparation not captured by our math test measure. To further address this concern, we run state-level regressions of college completion rates from the U.S. Census on the size of the college-age population. As argued by Bound and Turner (2007), the college-age population serves as an instrument for collegiate resources because demand shocks are unlikely to be fully accounted for by the public state budgeting system. We use this instrument in order to determine whether completion rates within states vary systematically with these demand shocks in order to give further evidence of the importance of collegiate resources in determining college completion rates. 


\section{Empirical Analysis of Changes in Completion Rates}

\section{A. Results from Completion Logits}

The coefficients from the completion logits estimated for the NLS72 sample and the NELS:88 sample are shown in Table 5 for the full sample and separately by initial school type. ${ }^{20}$ Overall, the coefficients shown in Table 5 have the expected signs: higher student-faculty ratios and lower math test percentiles lower the likelihood of completion. ${ }^{21}$ This pattern is evident within sectors as well. We find consistent evidence that increases in student-faculty ratios reduce completion, both for the full sample and within sectors. However, similar to Stange (2009), we find little evidence that measured collegiate resources affect the likelihood of completion in the community college sector. This result could be due to the fact that within-sector variation in institutional resources matters little in determining the likelihood of obtaining a BA for community college students. More plausibly, perhaps, our resource measures do a particularly poor job measuring resources devoted to the two-year college student potentially bound for a four-year school. Some of the most resource-intensive programs at community colleges are likely to be vocational programs of short duration. In addition, student-faculty ratios are a noisier resource measure in community colleges than in the other sectors of higher education because of the greater incidence of students attending less than full-time and faculty employed on an adjunct basis.

\footnotetext{
${ }^{20}$ In addition to the variables discussed in Section I, we include an indicator variable for whether the respondent has no information on student-faculty ratios and an interaction between this indicator and math percentiles. In both NLS72 and NELS:88, 10.8 percent have missing student-faculty ratios. These data are missing either because the student's first listed institution could not be matched with an institution in the HEGIS/IPEDS data or because the matched institution had missing HEGIS/IPEDS data. Rather than impute these ratios with very limited information, we include a dummy variable indicating missing status and allow the effect of missing institutional data to vary with math percentiles.

${ }^{21}$ Similarly, Audrey Light and Wayne Strayer (2000) find evidence using the National Longitudinal Survey of Youth that both college quality and student ability affect the likelihood of college completion.
} 
The initial school type indicators in the first two columns of Table 5 show that even conditional on student-faculty ratios, there is a significantly higher likelihood of completion at top 50 public and selective private schools and a significantly lower likelihood of completion at community colleges. ${ }^{22}$ These results suggest there are unobserved aspects of college quality across sectors not being proxied for by our institutional resource measure that are important in explaining college completion.

\section{B. Simulation Results for the Full Sample}

Results from the decomposition analysis are shown in Table $6 .{ }^{23}$ The observed cohort completion rates are presented in the first two rows, followed by the difference in the third row, and the difference between the observed NELS:88 completion rate and the counterfactual completion rate calculated using NELS:88 completion logit coefficients and all observables from the 1972 cohort are shown in the fourth row. Overall, the covariates in our analysis explain the entire decline in the completion rate.

In order to distinguish the effects of changes in variables like college preparation from the effects of changes in supply-side variables like student-faculty ratios, we use the decomposition methodology discussed in Section II. The subsequent rows of Table 6 show the predicted change in completion rates based on these univariate simulations. For the Change Due to Math Test Percentiles, we calculate the difference between the observed NELS:88 completion rate and the simulated completion rate that would have prevailed if the observations in NELS:88

\footnotetext{
${ }^{22}$ Researchers consistently have found college students starting at two-year schools are less likely to complete the BA than their peers beginning at four-year schools. C. Lockwood Reynolds (2007) and Darwin W. Miller (2007) use matching estimators to approach this question, while earlier work uses regression techniques to adjust for observable differences between those starting at two and four-year schools (Cecilia Rouse, 1995; Duane E. Leigh and Andrew M. Gill, 2003; Arturo Gonzales, Michael J. Hilmer, and Jonathon Sandy, 2006).

${ }^{23}$ Appendix B shows decompositions performed by multiplying either the average marginal effects from our logit models or the coefficients from a linear probability model on a given variable by the change in the mean value of the variable across surveys. In the former case, this amounts to the assumption that variable shifts were constant across the population, while in the later it amounts to the standard Blinder-Oaxaca decomposition. In both cases the results are qualitatively similar to those presented in Tables 6 and 7.
} 
were to possess the same math test percentile distribution as the NLS72 cohort, holding all other covariates constant. This simulation leads to a completion rate 1.6 percentage points higher than the observed completion rate in the NELS:88 sample. At the same time, shifting other individual characteristics (primarily parents' education) back to their 1972 levels would lower completion rates by a comparable amount. Conducting the same exercise for student-faculty ratios produces a completion rate 1.1 percentage points higher than the observed NELS:88 completion rates, while changing just institutional type produces a completion rate 3.5 percentage points higher than observed. These results underscore the importance of supply-side factors in explaining completion rate declines; shifts in where students enter the postsecondary system and changes in student-faculty ratios together explain the entire observed decline in completion rates across surveys. If we did not account for other student background characteristics shifting in ways that would suggest an increase in completion rates, observed declines in student preparation and supply-side factors would slightly over-explain the total observed decline.

\section{Simulation Results by Initial School Type}

Results from our decomposition analysis by initial school type also are shown in Table 6 . For students beginning college at non-top 50 public universities, the changes in math test percentiles explain none of the observed completion rate decline. This result occurs despite the fact that we find a sizeable positive effect of math tests on completion in this sector, as shown in Table 5. However, as Figure 3 illustrates, the math test percentiles of incoming students at nontop 50 public institutions have changed negligibly across surveys. Student preparation for college, as measured by math test percentiles, has not changed enough to explain the completion 
rate decline for non-top 50 ranked public university students. ${ }^{24}$ Instead, we find that the large increase in student-faculty ratios reported in Table 4 can explain 81.6 percent of the total observed drop in completion rates. At least for students in the non-top 50 public sector, supplyside shifts are the dominant explanation for why completion rates have declined across surveys.

For students at community colleges, variation in student-faculty ratios has little explanatory power, while observed declines in student preparation are notable. Reductions in the math test percentile of incoming students can explain 88 percent of the 2.5 percentage point decline in this sector. These results are consistent with the dramatic expansion of the community college sector across cohorts and the fact that the less prepared students induced to attend college in the later cohort are predominantly entering the postsecondary system through community colleges.

At private universities and the top-tier public universities, the results are quite different. Neither observable student characteristics nor institutional resource measures are particularly powerful in explaining the quite prominent increases in college completion rates. This result is not surprising-as discussed in Section II, increasing returns to education should raise completion rates unless they are coupled with resource declines or increases in attendance among less academically prepared students, neither of which occurred in these sectors.

\section{Simulation Results by Gender}

One of the striking results shown in Table 2 is the large difference in completion rate changes across genders. Our estimates show a cohort effect in college completion for women, with women in the later cohort completing college at much higher rates than their peers from the earlier cohort in most sectors of higher education. A compelling and plausible explanation for

\footnotetext{
${ }^{24}$ The fact that the math test percentile distribution changed negligibly in the non-top 50 public sector suggests peer effects cannot explain the decline in completion rates in this sector because the composition of peers has remained relatively constant.
} 
this shift is that labor market opportunities and the associated returns to college completion for women changed over this period, with women in the later cohort much more likely to expect extended labor force participation (Goldin, Katz, and Kuziemko, 2006). These labor market changes are powerful demand-side factors affecting college completion rates.

Table 7 shows results from our decomposition analysis done separately by gender, using the same logit coefficients as in Table 6 but generating within-gender counterfactual variable distributions. These decompositions allow us to account separately for the importance of the differences in the change in college preparation across genders and the differences between men and women in how they sort into the sectors of higher education across cohorts. Furthermore, because most of the decline in completion rates has been among men, it is important to determine whether we can explain the decline among the more affected group. The results for men, shown in Panel A, are similar to those in Table 6: while declines in math test percentiles can explain about a quarter of the observed completion rate drop, it is predominantly the shift across institutions combined with higher student-faculty ratios that are responsible for the aggregate decline. Taken together, these two supply-side factors explain about 55 percent of the completion rate drop for men, and our demand-side and supply-side factors together explain about 80 percent. For the public non-top 50 sample, these factors can account for 43.8 percent of the 9.6 percentage point decline, with student-faculty ratio increases acting as the driving force behind these results. In the community college sector, it is predominantly the decline in math test percentiles that can explain the overall completion rate drop, accounting for 69 percent of the observed reduction in completion. Overall, we can explain 82 percent of the total completion rate decline with our demand and supply side factors in this sector. 
For women, as shown in Panel B of Table 7, the total effect of supply-side factors and academic preparation is to overpredict the observed completion rate decline in the full sample as well as in the non-top 50 public and community college sectors. In the public top 50 and private sectors, women saw an increase in completion rates, but none of this increase is predicted by test percentile and student-faculty ratio changes. Particularly at top-tier institutions, the collegiate attainment of women conditional on measured academic achievement improved markedly between cohorts.

Overall, the closing of the gender gap in college preparation between men and women and the increasing likelihood that men and women attend similar colleges with similar resources explains some of the gender difference in the change in completion rates. However, as implied by the dramatic change in the coefficient on the male dummy in our completion rate logits (see Table 5), most of the relative change is not explained by any of the explanatory variables in our models. Changes in women's expectations about the future potentially explains this residual (Goldin, Katz and Kuziemko, 2006).

The increased participation of women in higher education between the 1972 and 1992 cohorts plausibly served to exacerbate supply constraints in the higher education market, particularly in the four-year sector. If not for the disproportionate increase in the enrollment of women, we expect that the distribution of men by type of initial enrollment would have reflected greater representation at four-year institutions with relatively high completion rates and lower enrollment at community colleges, as the four year sector is much less enrollment-elastic than the two-year sector. To frame this idea, we use the numbers in Tables 1 and 2 to calculate what the male completion rate would have been for the 1992 cohort had the overall enrollment shares remained constant at their 1992 levels (column iv of Table 1), but had the gender ratios within 
each category stayed at their 1972 levels. This simulation serves to increase the share of men attending private colleges, in general, and selective private colleges, in particular. Holding sector completion rates constant, we calculate that male completion rates for the 1992 cohort would have been three percent higher under this alternative regime. Thus, relatively inelastic supply in the most resource-intensive sectors of higher education served to generate crowd-out in the distribution of enrollment choices of men, which magnified the decline in completion rates for this group.

\section{E. State-Level Evidence of the Effect of Collegiate Resources on College Completion}

Since student-faculty ratios and high school math test percentiles may be imperfect proxies for institutional resources and college preparation, respectively, we present supplemental evidence on the link between changes in collegiate resources and changes in completion rates. Because states are the governmental level of control for public universities, we exploit withinstate changes in the college-age population that generate exogenous variation in the level of public higher education subsidies per student. Absence of full adjustment of public subsidies to student demand shocks means that relatively large cohorts face diluted resources per student at state-run institutions in what Bound and Turner (2007) describe as “cohort crowding.”

Using data from the 1940-1975 birth cohorts in the 2000 U.S. Census, we regress the log of the state and birth cohort share of the population with at least some college attaining a BA degree on log birth cohort size, including state and year fixed effects. The estimated coefficient on log cohort size provides a reduced form estimate of the elasticity of college completion with respect to cohort size; the basic approach parallels Bound and Turner (2007), though is distinguished in the focus on completion relative to college attendance. 
Our findings, presented in Table 8, show within-state increases in cohort size of ten percent lead to declines in the share of BA recipients among those starting college of between 1.12 percent and 1.85 percent. The separate outcomes for men and women, shown in the final two rows of Table 8, are similar in magnitude, though slightly more pronounced for men than for women. Our results support the hypothesis that increases in the number of students attempting to enroll in colleges and universities, particularly in public institutions, reduce both the rate of college entry and the rate of completion conditional on college entry. Overall, the results using the Census data provide further evidence of the empirical relevance of supply-side constraints in determining completion rates. ${ }^{25}$ Taken together with the results from the logit simulations, these estimates suggest that incomplete institutional adjustments to growth in the number of students pursuing a college degree may foster increased stratification, with an increasingly smaller portion of the student body receiving an increasingly larger fraction of the resources.

\section{Conclusion}

Focusing on the inter-cohort comparison of college completion rates between the NLS72 (the high school class of 1972) and NELS:88 (the high school class of 1992) cohorts, we find that declines in pre-collegiate preparation and changes in the distribution of supply-side options in the higher education market-reflecting both institutional type and resources within institutions-explain the substantial decline in college completion rates, particularly among men.

\footnotetext{
${ }^{25}$ An alternative explanation is that changes in the demand for college may be reduced among relatively large cohorts if college preparation is also linked to cohort size. Two related concerns surface. First, relatively large cohorts may be distinguished by adverse demographic or economic shocks that have direct effects on collegiate attainment. For example, if big cohorts are distinguished by low parental education or large family size, such "compositional effects" might account for reduced college completion rather than crowding out on the supply side of the market. Secondly, membership in a relatively large birth cohort may dilute educational resources at the elementary and secondary levels, which would also reduce college preparedness. Bound and Turner (2007) present evidence that neither of these effects is likely to account for much of the association between cohort size and college completion rates. In particular, using Census data, they found, at best, only a modest association between cohort size and the demographic composition of the college age population. They also found only a very modest effect of cohort size on the college preparedness of high school graduates.
} 
By examining the type of college at which individuals begin their postsecondary careers, we show the decrease in degree completion is largely concentrated among students beginning at non-top 50 public universities and two-year colleges. As such, the progression from college enrollment to BA receipt over the last three decades has become much more stratified as the differences in resources per student have grown both between sectors and within sectors.

We find increased enrollment among students from lower in the pre-collegiate math test score distribution, which is occurring solely at two-year schools, can explain about 33 percent of the overall drop in college completion rates. The drop in completion rates has not occurred equally across gender groups-we find large decreases among males but not females. That the college enrollment rate has increased more for women than for men, yet declines in college completion have been smaller for women than men, suggests changes in completion rates cannot be due solely to increases in enrollment by marginal students.

Our analysis focuses on the supply-side of higher education, which has not received much attention in previous literature. Changes in resources per student, as measured by studentfaculty ratios at the institution where a student begins college, account for about $1 / 4$ of the observed aggregate decline in the college completion rate. Similarly, we find the shift in the distribution of students' initial college type, largely the shift toward community colleges, explains roughly $3 / 4$ of the observed decrease in completion rates.

We argue one reason for the importance of the initial institution type in explaining reductions in completion probabilities is the increased stratification across sectors that has occurred over the time period covered by our analysis. This increased stratification in resources is likely a response to demand shocks combined with increased market integration that has produced more differentiation, leading to declines in resources per students outside the selective 
public and private universities where rationing occurs through selective admissions. Thus, while "access" or initial college enrollment has increased dramatically over the past three decades, many of the new students drawn to higher education (likely to take advantage of the increased returns to a BA) are attending institutions with fewer resources and are not graduating. The mechanisms by which this is occurring, however, deserve more attention in future research.

That decreases in college completion rates are concentrated among students attending public colleges and universities outside the most selective few suggests a need for more attention to the budgets of these institutions from state appropriations and tuition revenues. These institutions may face tradeoffs between fulfilling an open access mission by increasing enrollment at low tuition with reduced resources per student and either raising tuition, which may reduce "access,” or limiting enrollment in order to increase resources per student. In drawing attention to changes in the composition of students as well as the supply-side of the market for higher education as explanations for declining completion rates, this analysis suggests that improving the understanding of the factors determining the level of collegiate attainment has substantial implications for the expected trend in the college wage premium and long-run economic growth. 


\section{$\underline{\text { References }}$}

Altonji, Joseph G. 1993. "The Demand for and Return to Education When Education Outcomes are Uncertain.” Journal of Labor Economics, 11(1):48-83.

Barsky, Robert, John Bound, Kerwin Charles, and Joseph Lupton. 2002. "Accounting for the Black-White Wealth Gap: A Nonparametric Approach.” Journal of the American Statistical Association, 97(459): 663-673.

Bound, John, Michael Lovenheim, and Sarah Turner. 2007. "Understanding the Decrease in College Completion Rates and the Increased Time to the Baccalaureate Degree.” PSC Research Report No. 07-626.

Bound, John, and Sarah Turner. 2007. "Cohort Crowding: How Resources Affect Collegiate Attainment.” Journal of Public Economics, 91(5-6): 877-899.

DiNardo, John, Nicole M. Fortin, and Thomas Lemieux. 1996. "Labor Market Institutions and the Distribution of Wages: 1973-1993, A Semi-Parametric Approach.” Econometrica, 64(5): 1001-1044.

Firpo, Sergio, Nicole Fortin, and Thomas Lemieux. 2007. "Decomposing Wage Distributions using Recentered Influence Function Regressions.” Mimeo (June).

Goldin, Claudia, Lawrence F. Katz, and Ilyana Kuziemko. 2006. “The Homecoming of American College Women: The Reversal of the College Gender Gap” Journal of Economic Perspectives, 20(4): 133-156.

Gonzalez, Arturo, Hilmer, Michael J. and Sandy, Jonathon. 2006 “Alternative Paths to College Completion: The Effect of Attending a Two-Year School on the Probability of Completing a Four-Year Degree,” Economics of Education Review 25(4): 463-471.

Heckman, James J., Hidehiko Ichimura, and Petra E. Todd. 1997. "Matching as an Econometric Evaluation Estimator: Evidence from Evaluating a Job Training Program.” Review of Economic Studies, 64(4): 605-654.

Heckman, James J., Hidehiko Ichimura, and Petra E. Todd. 1998. "Matching as an Econometric Evaluation Estimator.” Review of Economic Studies, 65(2): 261-294.

Heckman, James J., and Paul A. Lafontaine. Forthcoming. “The American High School Graduation Rate: Trends and Levels.” Review of Economics and Statistics.

Heckman, James J., and Salvador Navarro. 2007. "Dynamic Discrete Choice and Dynamic Treatment Effects.” Journal of Econometrics, 136(2): 341-396.

Heckman, James J., Lance J. Lochner, and Petra E. Todd. 2008. “Earnings Functions and Rates of Return.” Journal of Human Capital, 2(1): 1-31. 
Hoxby, Caroline M. Forthcoming. “The Changing Selectivity of American Colleges.” Journal of Economic Perspectives.

Horvitz, Daniel G. and David J. Thompson. 1952. “A Generalization of Sampling Without Replacement from a Finite Universe.” Journal of the American Statistical Association 47: 663685.

Jaeger, David A. 1997. "Reconciling the Old and New Census Bureau Education Questions: Recommendations for Researchers.” Journal of Business and Economic Statistics 15(3):300-309.

Kane, Thomas J., Peter R. Orszag, and David L. Gunter. 2003. "State Fiscal Constraints and Higher Education Spending: The Role of Medicaid and the Business Cycle.” Brookings Institution Discussion Paper.

Leigh, Duane E., and Andrew M. Gill. 2003. "Do Community Colleges Really Divert Students from Earning Bachelor's Degrees?” Economics of Education Review, 22(1): 23-30.

Light, Audrey and Wayne Strayer. 2000. "Determinants of College Completion: School Quality or Student Ability?” Journal of Human Resources, 35(2): 299-332.

Little, Roderick J.A. 1982. “Models for Nonresponse in Sample Surveys.” Journal of the American Statistical Association, 77(378): 237-250.

Little, Roderick J.A., and Donald B. Rubin. 2002. Statistical Analysis with Missing Data, $2^{\text {nd }}$ Edition. New York: Wiley.

Miller, Darwin W. 2007. "Isolating the Causal Impact of Community College Enrollment on Educational Attainment and Labor Market Outcomes in Texas." Stanford Institute for Economic Policy Research Discussion Paper 0633.

Reynolds, C. 2007. "Academic and Labor Market Effects of Two-year College Attendance: Evidence Using Matching Methods.” Mimeo.

Rouse, Cecilia E. 1995. "Democratization or Diversion? The Effect of Community Colleges on Educational Attainment.” Journal of Business and Economic Statistics, 13(2): 217-224.

Rubin, Donald B. 1987. Multiple Imputation for Nonresponse in Surveys. New York: Wiley.

Santos, Laanan F. 2003. "Degree Aspirations of Two-Year College Students.” Community College Journal of Research and Practice, 27(6): 495-518.

Schafer, Joseph L. 1997. Analysis of Incomplete Multivariate Data. London: Chapman and Hall. 
Snyder, Thomas D., Alexandra G. Tan, and Charlene M. Hoffman. 2006. Digest of Education Statistics, 2005 (NCES 2006-030). U.S. Department of Education, National Center for Education Statistics. Washington, DC: U.S. Government Printing Office.

Stange, Kevin. 2009. "Ability Sorting and the Importance of College Quality to Student Achievement: Evidence from Community Colleges.” http://wwwpersonal.umich.edu/ kstange/papers/StangeCollegeQuality.pdf.

Stange, Kevin. 2008. "An Empirical Investigation of the Option Value of College Enrollment.” http://www-personal.umich.edu/ kstange/papers/StangeOptionValue.pdf.

U.S. Department of Education, National Center for Education Statistics. Higher Education General Information Survey (HEGIS), "Degrees and Other Formal Awards Conferred” surveys, and Integrated Postsecondary Education Data System (IPEDS), "Completions” surveys.

Weisbrod, Burton A. 1962. “Education and Investment in Human Capital.” Journal of Political Economy 70(5), Part 2: 106-123. 
Table 1. Changes over Time in Type of First Institution for All Attendees and For Those Obtaining a BA within Eight Years of Cohort High School Graduation

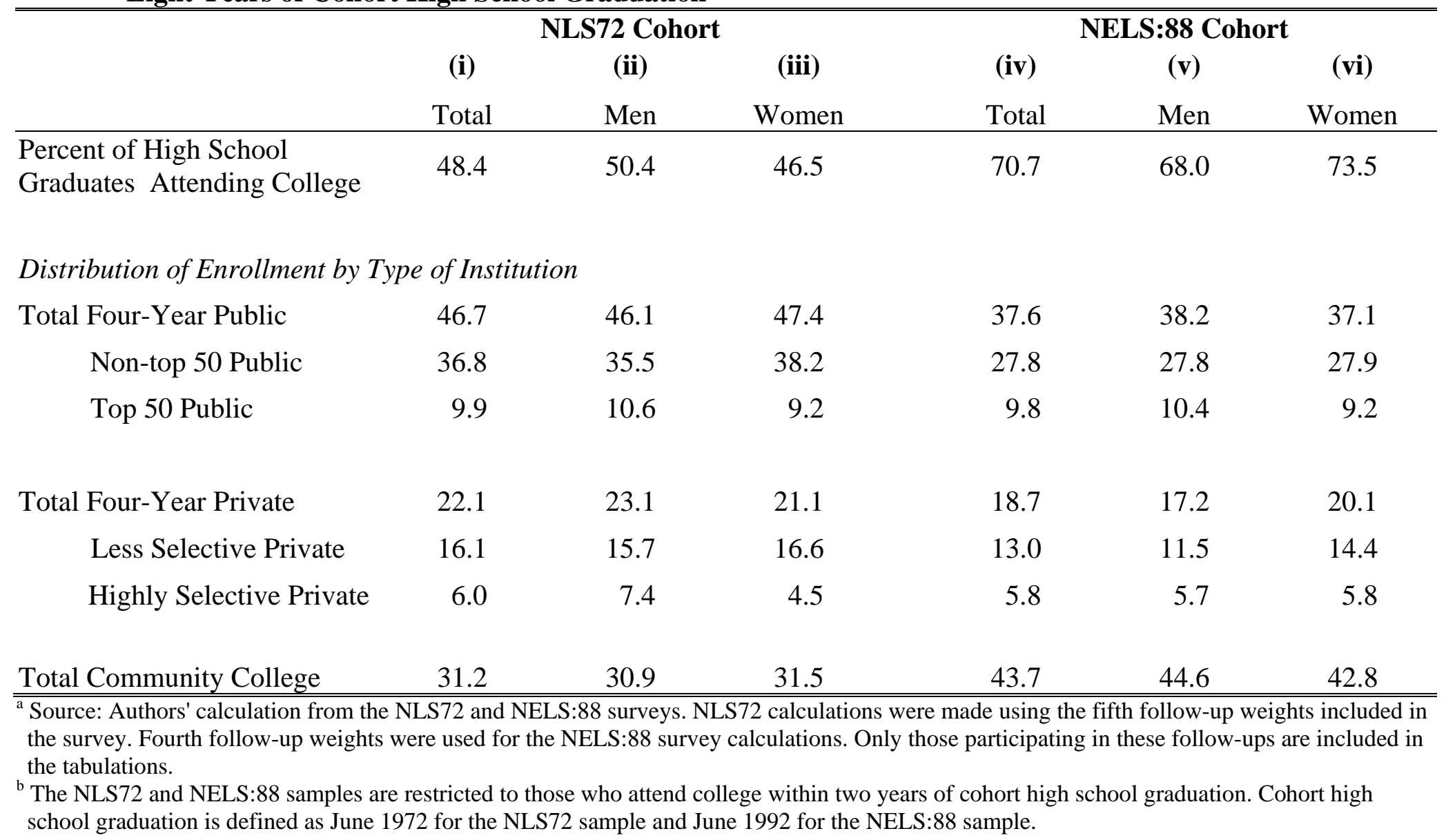


Table 2. Completion Rates (in Percent) within 8 Years of Cohort High School Graduation for the Full Sample and by First Institution

\begin{tabular}{|c|c|c|c|c|c|c|c|c|c|}
\hline \multirow[b]{2}{*}{ Sample } & \multicolumn{3}{|c|}{ Total } & \multicolumn{3}{|c|}{ Men } & \multicolumn{3}{|c|}{ Women } \\
\hline & NLS72 & NELS:88 & Difference & NLS72 & NELS:88 & Difference & NLS72 & NELS:88 & Difference \\
\hline Full Sample & 50.5 & 45.9 & $\begin{array}{l}-4.6^{* *} \\
(1.5)\end{array}$ & 51.7 & 43.2 & $\begin{array}{l}-8.5^{* *} \\
(2.0)\end{array}$ & 49.2 & 48.5 & $\begin{array}{l}-0.8 \\
(2.0)\end{array}$ \\
\hline Initial Institution Type & & & & & & & & & \\
\hline Total Four-Year Public & 64.3 & 63.5 & $\begin{array}{l}-0.8 \\
(2.3)\end{array}$ & 64.1 & 58.7 & $\begin{array}{l}-5.4^{*} \\
(2.8)\end{array}$ & 64.5 & 68.1 & $\begin{array}{c}3.7 \\
(3.1)\end{array}$ \\
\hline Non-top 50 Public & 61.8 & 56.9 & $\begin{array}{l}-4.9 * \\
(2.6)\end{array}$ & 61.2 & 51.6 & $\begin{array}{l}-9.6^{* *} \\
(3.3)\end{array}$ & 62.4 & 61.8 & $\begin{array}{l}-0.6 \\
(3.6)\end{array}$ \\
\hline Top 50 Public & 73.5 & 82.5 & $\begin{array}{l}9.0 * * \\
(2.8)\end{array}$ & 73.8 & 77.5 & $\begin{array}{c}3.8 \\
(4.1)\end{array}$ & 73.1 & 87.7 & $\begin{array}{l}14.6 * * \\
(3.5)\end{array}$ \\
\hline Total Four-Year Private & 64.1 & 76.6 & $\begin{array}{l}12.5^{* *} \\
(2.9)\end{array}$ & 67.2 & 74.8 & $\begin{array}{l}7.8^{*} \\
(4.1)\end{array}$ & 60.6 & 78.0 & $\begin{array}{l}17.2 * * \\
(3.9)\end{array}$ \\
\hline Less Selective Private & 58.2 & 70.5 & $\begin{array}{l}12.3^{* *} \\
(3.5)\end{array}$ & 59.9 & 67.7 & $\begin{array}{c}8.0 \\
(5.3)\end{array}$ & 56.5 & 72.6 & $\begin{array}{l}15.9 * * \\
(4.6)\end{array}$ \\
\hline $\begin{array}{l}\text { Highly Selective } \\
\text { Private }\end{array}$ & 80.1 & 90.3 & $\begin{array}{l}10.3^{* *} \\
(3.3)\end{array}$ & 82.7 & 89.2 & $\begin{array}{c}6.5 \\
(4.3)\end{array}$ & 75.6 & 91.4 & $\begin{array}{l}15.8^{* *} \\
(5.0)\end{array}$ \\
\hline $\begin{array}{l}\text { Total Community } \\
\text { College }\end{array}$ & 20.2 & 17.6 & $\begin{array}{l}-2.5 \\
(1.7)\end{array}$ & 21.6 & 17.7 & $\begin{array}{l}-3.9 * \\
(2.3)\end{array}$ & 18.6 & 17.5 & $\begin{array}{l}-1.1 \\
(2.4)\end{array}$ \\
\hline
\end{tabular}

${ }^{\mathrm{a}}$ Source: Authors' calculation from the NLS72 and NELS:88 surveys. NLS72 calculations were made using the fifth follow-up weights included in the survey. Fourth follow-up weights were used for the NELS:88 survey calculations. Only those participating in these follow-ups are included in the tabulations.

${ }^{\mathrm{b}}$ The NLS72 and NELS:88 samples are restricted to those who attend college within two years of cohort high school graduation. Cohort high school graduation is defined as June 1972 for the NLS72 sample and June 1992 for the NELS:88 sample.

${ }^{\mathrm{c}}$ The difference between NELS:88 and NLS72 is in each third column. The standard error of this difference is in parentheses and is clustered at the high-school level, which is the primary sampling unit.

** Significantly different from 0 at the $5 \%$ level.

* Significantly different from 0 at the $10 \%$ level. 
Table 4. Undergraduate Student-Faculty Ratios and Expenditures per Student by Initial School Type Panel A: Full Sample

\begin{tabular}{|c|c|c|c|c|c|c|}
\hline \multirow[b]{3}{*}{ Survey } & \multicolumn{5}{|c|}{ Student-Faculty Ratios } & \multirow{3}{*}{$\begin{array}{c}\text { Median } \\
\text { Expenditures } \\
\text { Per Student } \\
\end{array}$} \\
\hline & \multirow[b]{2}{*}{ Mean } & \multicolumn{4}{|c|}{ Percentile } & \\
\hline & & $25^{\text {th }}$ & $50^{\text {th }}$ & $75^{\text {th }}$ & $90^{\text {th }}$ & \\
\hline NLS72 & 29.5 & 20.8 & 25.2 & 33.1 & 50.7 & $\$ 4,716$ \\
\hline NELS:88 & 39.1 & 22.7 & 30.4 & 52.7 & 71.5 & $\$ 4,339$ \\
\hline \multicolumn{7}{|c|}{ Panel B: Public 4-Year Non-top 50} \\
\hline \multirow[b]{3}{*}{ Survey } & \multicolumn{5}{|c|}{ Student-Faculty Ratios } & Median \\
\hline & \multicolumn{5}{|c|}{$\begin{array}{l}\text { Percentile } \\
\end{array}$} & Expenditures \\
\hline & Mean & $25^{\text {th }}$ & $50^{\text {th }}$ & $75^{\text {th }}$ & $90^{\text {th }}$ & Per Student \\
\hline NLS72 & 25.5 & 20.9 & 24.6 & 28.8 & 32.7 & $\$ 5,331$ \\
\hline NELS:88 & 29.1 & 23.7 & 27.3 & 33.0 & 39.9 & $\$ 5,102$ \\
\hline \multicolumn{7}{|c|}{ Panel C: Public 4-Year Top 50} \\
\hline \multirow[b]{3}{*}{ Survey } & \multicolumn{5}{|c|}{ Student-Faculty Ratios } & Median \\
\hline & \multicolumn{5}{|c|}{$\begin{array}{l}\text { Percentile } \\
\end{array}$} & Expenditures \\
\hline & Mean & $25^{\text {th }}$ & $50^{\text {th }}$ & $75^{\text {th }}$ & $90^{\text {th }}$ & Per Student \\
\hline NLS72 & 23.0 & 20.8 & 22.7 & 24.1 & 30.7 & $\$ 7,871$ \\
\hline NELS:88 & 22.4 & 20.5 & 22.2 & 25.1 & 26.3 & $\$ 9,663$ \\
\hline \multicolumn{7}{|c|}{ Panel D: Private 4-Year Less Selective } \\
\hline \multirow[b]{3}{*}{ Survey } & \multicolumn{5}{|c|}{ Student-Faculty Ratios } & Median \\
\hline & \multicolumn{5}{|c|}{ Percentile } & Expenditures \\
\hline & Mean & $25^{\text {th }}$ & $50^{\text {th }}$ & $75^{\text {th }}$ & $90^{\text {th }}$ & Per Student \\
\hline NLS72 & 23.4 & 16.6 & 20.8 & 26.7 & 34.7 & $\$ 4,732$ \\
\hline NELS:88 & 25.7 & 17.3 & 21.9 & 27.0 & 37.2 & $\$ 5,269$ \\
\hline
\end{tabular}

Panel E: Private 4-Year Highly Selective

\begin{tabular}{|c|c|c|c|c|c|c|}
\hline \multirow[b]{3}{*}{ Survey } & \multicolumn{5}{|c|}{ "Student-Faculty Ratios } & \multirow{3}{*}{$\begin{array}{c}\text { Median } \\
\text { Expenditures } \\
\text { Per Student }\end{array}$} \\
\hline & \multirow[b]{2}{*}{ Mean } & \multicolumn{3}{|c|}{ Percentile } & \multirow[b]{2}{*}{$90^{\text {th }}$} & \\
\hline & & $25^{\text {th }}$ & $50^{\text {th }}$ & $75^{\text {th }}$ & & \\
\hline NLS72 & 19.1 & 14.5 & 19.8 & 23.8 & 25.4 & $\$ 7,646$ \\
\hline NELS:88 & 18.6 & 13.3 & 17.6 & 23.3 & 28.3 & $\$ 13,782$ \\
\hline \multicolumn{7}{|c|}{ Panel F: 2-Year } \\
\hline \multirow[b]{3}{*}{ Survey } & \multicolumn{5}{|c|}{ "Student-Faculty Ratios } & Median \\
\hline & & \multicolumn{4}{|c|}{ Percentile } & Expenditures \\
\hline & Mean & $25^{\text {th }}$ & $50^{\text {th }}$ & $75^{\text {th }}$ & $90^{\text {th }}$ & Per Student \\
\hline NLS72 & 41.8 & 29.2 & 38.5 & 52.5 & 68.1 & $\$ 3,068$ \\
\hline NELS:88 & 58.5 & 39.8 & 57.8 & 71.4 & 92.5 & $\$ 2,610$ \\
\hline
\end{tabular}

Source: Data on faculty, enrollment, and expenditures are from the HEGIS/IPEDS surveys from the Department of Education. Expenditures per student are for instructional expenditures only. All financial figures are in real \$2007 and are deflated by the Higher Education Price Index (HEPI). Tabulations are weighted by the fifth follow-up weights in NLS72 and are weighted by the fourth follow-up weights in NELS:88. 
Table 5. Completion Logits by Survey and Initial School Type

\begin{tabular}{|c|c|c|c|c|c|c|}
\hline $\begin{array}{l}\text { anel A. NLS/2 R } \\
\text { Ind.Var. }\end{array}$ & $\begin{array}{l}\text { Full } \\
\text { Sample }\end{array}$ & $\begin{array}{l}\text { Public } \\
\text { Non- } \\
\text { Top } 50\end{array}$ & $\begin{array}{l}\text { Public } \\
\text { Top } 50\end{array}$ & $\begin{array}{l}\text { Private } \\
\text { Less } \\
\text { Selective }\end{array}$ & $\begin{array}{l}\text { Private } \\
\text { Highly } \\
\text { Selective }\end{array}$ & $\begin{array}{l}\text { Comm. } \\
\text { College }\end{array}$ \\
\hline \multirow{2}{*}{$\operatorname{Ln}\left(\frac{\text { Student }}{\text { Faculty }}\right)$} & -0.514 & -0.603 & -0.583 & -0.829 & -0.765 & -0.281 \\
\hline & $(0.134)$ & $(0.284)$ & (0.449) & $(0.252)$ & (0.621) & $(0.196)$ \\
\hline Missing $\frac{\text { Student }}{}$ & -1.495 & -0.948 & -1.788 & -2.483 & -3.507 & -1.772 \\
\hline Faculty & (0.677) & $(1.192)$ & (1.991) & (1.178) & (2.318) & (0.989) \\
\hline Math Percentile & $\begin{array}{r}0.019 \\
(0.003)\end{array}$ & $\begin{array}{r}0.016 \\
(0.004)\end{array}$ & $\begin{array}{r}0.022 \\
(0.006)\end{array}$ & $\begin{array}{r}0.025 \\
(0.005)\end{array}$ & $\begin{array}{r}0.023 \\
(0.011)\end{array}$ & $\begin{array}{r}0.019 \\
(0.004)\end{array}$ \\
\hline Missing $\frac{\text { Student }}{\text { Faculty }} *$ & -0.005 & -0.015 & 0.001 & -0.009 & -0.002 & 0.014 \\
\hline (Math Percentile) & $(0.007)$ & $(0.011)$ & $(0.019)$ & $(0.011)$ & $(0.016)$ & $(0.010)$ \\
\hline Income 6000/20000 & $\begin{array}{r}0.038 \\
(0.329)\end{array}$ & $\begin{array}{r}-0.028 \\
(0.508)\end{array}$ & $\begin{array}{r}-0.542 \\
(0.616)\end{array}$ & $\begin{array}{r}0.595 \\
(0.643)\end{array}$ & $\begin{array}{r}0.814 \\
(1.346)\end{array}$ & $\begin{array}{r}-0.081 \\
(0.375)\end{array}$ \\
\hline \multirow{2}{*}{$\begin{array}{l}\text { Income } 7500 / 25000 \\
\text { Income }\end{array}$} & $\begin{array}{r}0.58 \\
(0.315)\end{array}$ & $\begin{array}{r}0.696 \\
(0.513)\end{array}$ & $\begin{array}{r}0.554 \\
(0.586)\end{array}$ & $\begin{array}{r}1.279 \\
(0.655)\end{array}$ & $\begin{array}{r}1.725 \\
(1.557)\end{array}$ & $\begin{array}{r}-0.184 \\
(0.450)\end{array}$ \\
\hline & 0.386 & 0.669 & -0.08 & 0.855 & 1.448 & -0.381 \\
\hline \multirow{2}{*}{$\begin{array}{l}\text { 10500/35000 } \\
\text { Income }\end{array}$} & $(0.307)$ & $(0.449)$ & $(0.541)$ & $(0.612)$ & (1.128) & $(0.390)$ \\
\hline & 0.329 & 0.414 & 0.094 & 1.102 & & -0.425 \\
\hline $15000 / 50000$ & $(0.314)$ & $(0.477)$ & $(0.557)$ & $(0.623)$ & & $(0.373)$ \\
\hline \multirow{3}{*}{$\begin{array}{c}\text { Income } \\
15000+/ 50000+\end{array}$} & 0.323 & 0.434 & 0.038 & 0.728 & 1.998 & -0.25 \\
\hline & $(0.312)$ & $(0.467)$ & $(0.554)$ & $(0.626)$ & $(1.256)$ & $(0.371)$ \\
\hline & $\begin{array}{r}0.002 \\
(0.125)\end{array}$ & $\begin{array}{r}-0.159 \\
(0.203)\end{array}$ & $\begin{array}{r}0.013 \\
(0.350)\end{array}$ & $\begin{array}{r}0.14 \\
(0.245)\end{array}$ & $\begin{array}{r}-1.148 \\
(0.726)\end{array}$ & $\begin{array}{r}0.261 \\
(0.175)\end{array}$ \\
\hline \multirow{3}{*}{$\begin{array}{l}\text { Father Some } \\
\text { College }\end{array}$} & 0.251 & 0.267 & -0.062 & 0.223 & -1.174 & 0.516 \\
\hline & $(0.134)$ & $(0.225)$ & $(0.365)$ & $(0.268)$ & $(0.720)$ & $(0.197)$ \\
\hline & 0.435 & 0.302 & 0.723 & 0.445 & -1.751 & 0.822 \\
\hline \multirow{4}{*}{$\begin{array}{c}\text { Father BA } \\
\text { Father Graduate } \\
\text { School }\end{array}$} & $(0.170)$ & $(0.270)$ & $(0.396)$ & $(0.346)$ & $(0.752)$ & $(0.294)$ \\
\hline & 0.73 & 0.423 & 0.871 & 1.019 & -0.588 & 0.897 \\
\hline & $(0.177)$ & $(0.285)$ & $(0.437)$ & $(0.372)$ & $(0.833)$ & $(0.286)$ \\
\hline & 0.143 & 0.16 & -0.135 & 0.071 & 0.877 & 0.08 \\
\hline \multirow{2}{*}{$\begin{array}{l}\text { Mother HS Diploma } \\
\text { Mother Some }\end{array}$} & $(0.131)$ & $(0.211)$ & (0.353) & $(0.280)$ & $(0.645)$ & (0.185) \\
\hline & 0.038 & -0.027 & -0.2 & -0.127 & 1.176 & 0.081 \\
\hline \multirow{2}{*}{$\begin{array}{l}\text { Mother Some } \\
\text { College }\end{array}$} & $(0.142)$ & $(0.226)$ & $(0.363)$ & $(0.340)$ & $(0.690)$ & $(0.209)$ \\
\hline & 0.296 & 0.347 & 0.116 & 0.114 & 0.964 & 0.344 \\
\hline Mother BA & $(0.176)$ & $(0.261)$ & $(0.431)$ & $(0.431)$ & (0.715) & $(0.244)$ \\
\hline \multirow{3}{*}{$\begin{array}{c}\text { Mother Graduate } \\
\text { School }\end{array}$} & 0.873 & 0.28 & 0.385 & 0.396 & 2.537 & 1.484 \\
\hline & $(0.400)$ & $(0.401)$ & $(0.645)$ & $(0.551)$ & (1.139) & $(0.681)$ \\
\hline & 0.941 & 1.191 & 1.969 & 1.483 & & 0.282 \\
\hline \multirow{2}{*}{ Asian } & $(0.292)$ & (0.615) & $(1.266)$ & (1.120) & & $(0.481)$ \\
\hline & -0.083 & -0.352 & 0.522 & 0.234 & 1.1 & -0.156 \\
\hline \multirow[t]{2}{*}{ Hispanic } & $(0.228)$ & $(0.378)$ & (0.617) & $(0.626)$ & $(0.997)$ & $(0.350)$ \\
\hline & 0.208 & 0.127 & 0.59 & 0.766 & -1.185 & -0.083 \\
\hline \multirow[t]{2}{*}{ Black } & $(0.206)$ & (0.307) & (0.601) & $(0.361)$ & (0.573) & (0.327) \\
\hline & -0.1 & -0.21 & -0.05 & -0.059 & 0.043 & 0.019 \\
\hline Male & $(0.087)$ & $(0.121)$ & $(0.204)$ & $(0.228)$ & $(0.329)$ & (0.137) \\
\hline Public Top 50 & 0.199 & & & & & \\
\hline
\end{tabular}




\begin{tabular}{crrrrrr} 
& $(0.116)$ & & & & & \\
Private Less & -0.252 & & & & & \\
Selective & $(0.128)$ & & & & & \\
Private Highly & 0.39 & & & & & \\
Selective & $(0.167)$ & & & & & \\
& -1.54 & & & & & \\
Community College & $(0.104)$ & & & & & \\
& 0.341 & 0.845 & 0.945 & 0.173 & 0.63 & -1.696 \\
Constant & $(0.543)$ & $(0.996)$ & $(1.617)$ & $(0.991)$ & $(2.335)$ & $(0.908)$ \\
\hline
\end{tabular}

Page 39 
Table 5. Completion Logits by Survey and Initial School Type (continued)

Panel B. NELS:88 Regressions

\begin{tabular}{|c|c|c|c|c|c|c|}
\hline Ind.Var. & $\begin{array}{c}\text { Full } \\
\text { Sample }\end{array}$ & $\begin{array}{c}\text { Public } \\
\text { Non- } \\
\text { Top } 50 \\
\end{array}$ & $\begin{array}{l}\text { Public } \\
\text { Top } 50\end{array}$ & $\begin{array}{c}\text { Private } \\
\text { Less } \\
\text { Selective } \\
\end{array}$ & $\begin{array}{c}\text { Private } \\
\text { Highly } \\
\text { Selective } \\
\end{array}$ & $\begin{array}{l}\text { Comm. } \\
\text { College }\end{array}$ \\
\hline \multirow{4}{*}{$\begin{array}{c}\operatorname{Ln}\left(\frac{\text { Student }}{\text { Faculty }}\right) \\
\text { Missing } \frac{\text { Student }}{\text { Faculty }}\end{array}$} & -0.398 & -1.547 & -2.774 & -0.629 & -0.667 & -0.132 \\
\hline & $(0.166)$ & (0.355) & $(0.860)$ & $(0.210)$ & $(0.725)$ & $(0.200)$ \\
\hline & -3.238 & -6.53 & -6.532 & -3.729 & 0 & -2.219 \\
\hline & $(0.767)$ & (1.839) & (3.184) & $(1.241)$ & $(0.000)$ & (1.022) \\
\hline \multirow{2}{*}{$\begin{array}{c}\text { Math Percentile } \\
\text { Missing } \frac{\text { Student }}{\text { Faculty }} *\end{array}$} & $\begin{array}{r}0.022 \\
(0.002)\end{array}$ & $\begin{array}{r}0.019 \\
(0.003)\end{array}$ & $\begin{array}{r}0.037 \\
(0.008)\end{array}$ & $\begin{array}{r}0.026 \\
(0.005)\end{array}$ & $\begin{array}{r}0.009 \\
(0.014)\end{array}$ & $\begin{array}{r}0.024 \\
(0.004)\end{array}$ \\
\hline & 0.019 & 0.027 & -0.026 & 0.021 & 0 & 0.008 \\
\hline (Math Percentile) & $(0.006)$ & $(0.024)$ & $(0.025)$ & $(0.005)$ & $(0.000)$ & $(0.011)$ \\
\hline \multirow[t]{2}{*}{ Income $6000 / 20000$} & $\begin{array}{r}-0.017 \\
(0.234)\end{array}$ & $\begin{array}{r}0.03 \\
(0.355)\end{array}$ & $\begin{array}{r}-0.584 \\
(1.038)\end{array}$ & $\begin{array}{r}-0.401 \\
(0.885)\end{array}$ & $\begin{array}{r}-2.325 \\
(1.625)\end{array}$ & $\begin{array}{r}0.208 \\
(0.444)\end{array}$ \\
\hline & $\begin{array}{r}0.324 \\
(0.300)\end{array}$ & $\begin{array}{r}-0.014 \\
(0.440)\end{array}$ & $\begin{array}{r}-0.737 \\
(0.934)\end{array}$ & $\begin{array}{r}-0.157 \\
(0.721)\end{array}$ & $\begin{array}{r}-1.956 \\
(1.665)\end{array}$ & $\begin{array}{r}0.991 \\
(0.595)\end{array}$ \\
\hline $\begin{array}{l}\text { Income } 7500 / 25000 \\
\text { Income }\end{array}$ & 0.174 & 0.013 & -1.546 & 0.032 & -2.741 & 0.7 \\
\hline \multirow{2}{*}{$10500 / 35000$} & $(0.262)$ & $(0.402)$ & $(0.965)$ & $(0.736)$ & (1.463) & $(0.416)$ \\
\hline & 0.316 & 0.344 & -0.475 & 0.025 & & 0.706 \\
\hline \multirow[t]{2}{*}{$15000 / 50000$} & $(0.224)$ & $(0.366)$ & $(0.853)$ & $(0.628)$ & & $(0.386)$ \\
\hline & 0.617 & 0.533 & -0.731 & 0.407 & -1.662 & 1.083 \\
\hline \multirow[t]{2}{*}{$15000+/ 50000+$} & $(0.249)$ & $(0.359)$ & $(0.901)$ & $(0.700)$ & $(1.480)$ & $(0.395)$ \\
\hline & 0.032 & -0.095 & -0.251 & 0.622 & 1.386 & 0.08 \\
\hline \multirow{4}{*}{$\begin{array}{l}\text { Father HS Diploma } \\
\text { Father Some } \\
\text { College }\end{array}$} & $(0.229)$ & $(0.378)$ & $(1.022)$ & $-(0.594)$ & $(1.520)$ & $(0.488)$ \\
\hline & 0.369 & 0.272 & -0.012 & 0.825 & 0.188 & 0.38 \\
\hline & $(0.249)$ & (0.439) & (1.007) & $(0.514)$ & $(1.404)$ & $(0.467)$ \\
\hline & 0.452 & 0.681 & 0.076 & 0.747 & 0.866 & 0.187 \\
\hline \multirow{4}{*}{$\begin{array}{c}\text { Father BA } \\
\text { Father Graduate } \\
\text { School }\end{array}$} & $(0.273)$ & (0.439) & (0.888) & $(0.491)$ & (1.492) & (0.511) \\
\hline & 0.83 & 0.617 & 1.169 & 1.276 & 1.466 & 0.753 \\
\hline & $(0.307)$ & $(0.535)$ & $(0.975)$ & $(0.757)$ & (1.443) & (0.532) \\
\hline & 0.215 & 0.249 & -0.837 & 0.464 & -1.292 & 0.121 \\
\hline \multirow{4}{*}{$\begin{array}{l}\text { Mother HS Diploma } \\
\text { Mother Some } \\
\text { College }\end{array}$} & $(0.274)$ & (0.380) & (1.269) & (0.590) & (1.364) & $(0.344)$ \\
\hline & 0.381 & 0.556 & -0.561 & 0.285 & 1.521 & 0.17 \\
\hline & $(0.287)$ & $(0.460)$ & (1.053) & $(0.548)$ & (1.489) & $(0.348)$ \\
\hline & 0.463 & 0.468 & -0.513 & 0.493 & 0.459 & 0.516 \\
\hline \multirow{4}{*}{$\begin{array}{l}\text { Mother BA } \\
\text { Mother Graduate } \\
\text { School }\end{array}$} & $(0.342)$ & (0.481) & (1.246) & (0.488) & (1.320) & (0.387) \\
\hline & 0.331 & 0.339 & -0.373 & 0.404 & 0.48 & 0.325 \\
\hline & $(0.340)$ & (0.520) & (1.199) & (0.856) & (1.425) & $(0.564)$ \\
\hline & 0.379 & 0.142 & 0.707 & -0.226 & & 0.637 \\
\hline \multirow[t]{2}{*}{ Asian } & $(0.253)$ & (0.331) & $(0.658)$ & (0.637) & & $(0.356)$ \\
\hline & -0.248 & 0.258 & -0.726 & -0.153 & -0.355 & -0.459 \\
\hline \multirow[t]{2}{*}{ Hispanic } & (0.169) & (0.293) & (0.543) & (0.419) & (1.190) & $(0.253)$ \\
\hline & $\begin{array}{r}-0.255 \\
(0.223)\end{array}$ & $\begin{array}{r}-0.631 \\
(0.263)\end{array}$ & $\begin{array}{r}-0.125 \\
(0.439)\end{array}$ & $\begin{array}{r}0.536 \\
(0.401)\end{array}$ & $\begin{array}{r}-0.902 \\
(1.111)\end{array}$ & $\begin{array}{r}-0.014 \\
(0.411)\end{array}$ \\
\hline Black & -0.549 & -0.709 & -0.913 & -0.378 & -0.433 & -0.414 \\
\hline Male & $(0.091)$ & (0.133) & $(0.357)$ & $(0.192)$ & $(0.484)$ & $(0.151)$ \\
\hline
\end{tabular}


Table 6. Logit Simulation Decompositions based on NELS:88 Estimates of College Completion by Type of Institution

\begin{tabular}{|c|c|c|c|c|c|c|}
\hline & $\begin{array}{c}\text { Full } \\
\text { Sample }\end{array}$ & $\begin{array}{c}\text { Public } \\
\text { Non-Top } \\
50 \\
\end{array}$ & $\begin{array}{l}\text { Public } \\
\text { Top } 50\end{array}$ & $\begin{array}{c}\text { Private } \\
\text { Less } \\
\text { Selective } \\
\end{array}$ & $\begin{array}{c}\text { Private } \\
\text { Highly } \\
\text { Selective }\end{array}$ & $\begin{array}{c}\text { Community } \\
\text { College }\end{array}$ \\
\hline NLS72 & 50.5 & 61.8 & 73.5 & 58.2 & 80.1 & 20.2 \\
\hline NELS:88 & 45.9 & 56.9 & 82.5 & 70.5 & 90.3 & 17.6 \\
\hline Total Change & -4.6 & -4.9 & 9.0 & 12.3 & 10.3 & -2.5 \\
\hline Change Due to Observables (X) & -4.5 & -0.6 & 3.7 & 3.2 & 11.0 & -3.6 \\
\hline Change Due to Student Characteristics & 0.1 & 3.4 & 2.6 & 3.8 & 10.4 & -3.1 \\
\hline Math Test Percentiles & -1.6 & 0.3 & 0.6 & -0.1 & 0.2 & -2.2 \\
\hline Other Student Characteristics & 1.7 & 3.1 & 2.0 & 3.9 & 10.2 & -0.9 \\
\hline Change Due to Supply-Side Factors & -4.6 & -4.0 & 1.1 & -0.6 & 0.6 & -0.5 \\
\hline Student-Faculty Ratios & -1.1 & -4.0 & 1.1 & -0.6 & 0.6 & -0.5 \\
\hline Initial School Types & -3.5 & & & & & \\
\hline Residual & -0.1 & -4.3 & 5.3 & 9.1 & -0.8 & 1.0 \\
\hline
\end{tabular}

\footnotetext{
${ }^{\text {a }}$ Source: Authors' calculations as described in the text from the NLS72 and NELS:88 surveys . NLS72 calculations were made using the fifth follow-up weights included in the survey. Fourth follow-up weights were used for the NELS:88 survey calculations. Only those participating in these follow-ups are included in the regression. School type samples refer to first institution attended. The NLS72 and NELS:88 samples are restricted to those who attend college within two years of cohort high school graduation. Cohort high school graduation is defined as June 1972 for the NLS72 sample and June 1992 for the NELS:88 sample.

${ }^{\mathrm{b}}$ The Change Due to Observables is the difference between the observed NELS:88 completion rate and the simulated NELS:88 completion rate using the distribution of all observables from NLS72. The changes due to math test percentiles, student-faculty ratios and initial school types are the differences between the observed NELS:88 completion rate and the simulated NELS:88 completion rates in which we simulate the completion rate if the each variable were distributed as in the NLS72 survey and all other observables were unchanged. The Change Due to Supply Side Factors is the sum of the changes due to student-faculty ratios and initial school types. We calculate the Change Due to Student Characteristics as the difference between the Change Due to Observables (X) and the Change Due to Supply-Side Factors. The Change Due to Other Student Characteristics is calculated by subtracting the Change Due to Math Test Percentiles from the Change Due to Student Characteristics.

${ }^{c}$ Data on faculty and enrollment are from the HEGIS/IPEDS surveys from the Department of Education.
} 
Table 7. Logit Simulation Decompositions based on NELS:88 Estimates of College Completion by Type of Institution and Gender

\begin{tabular}{|c|c|c|c|c|c|c|}
\hline \multicolumn{7}{|c|}{ Panel A: Men } \\
\hline & $\begin{array}{c}\text { Full } \\
\text { Sample }\end{array}$ & $\begin{array}{c}\text { Public } \\
\text { Non-Top } \\
50 \\
\end{array}$ & $\begin{array}{l}\text { Public } \\
\text { Top } 50\end{array}$ & $\begin{array}{c}\text { Private } \\
\text { Less } \\
\text { Selective }\end{array}$ & $\begin{array}{c}\text { Private } \\
\text { Highly } \\
\text { Selective }\end{array}$ & $\begin{array}{c}\text { Community } \\
\text { College }\end{array}$ \\
\hline NLS72 & 51.7 & 61.2 & 73.8 & 59.9 & 82.7 & 21.6 \\
\hline NELS:88 & 43.2 & 51.6 & 77.5 & 67.7 & 89.2 & 17.7 \\
\hline Total Change & -8.5 & -9.6 & 3.7 & 7.8 & 6.5 & -3.9 \\
\hline Change Due to Observables (X) & -5.6 & -1.4 & 8.4 & 3.4 & 12.0 & -3.0 \\
\hline Change Due to Student Characteristics & -0.9 & 2.2 & 7.2 & 3.9 & 11.5 & -2.5 \\
\hline Math Test Percentiles & -2.1 & -0.6 & -0.3 & -3.2 & 0.1 & -2.7 \\
\hline Other Student Characteristics & 1.2 & 2.8 & 7.5 & 7.1 & 11.4 & 0.2 \\
\hline Change Due to Supply-Side Factors & -4.7 & -3.6 & 1.2 & -0.5 & 0.5 & -0.5 \\
\hline Student-Faculty Ratios & -1.0 & -3.6 & 1.2 & -0.5 & 0.5 & -0.5 \\
\hline Initial School Types & -3.7 & & & & & \\
\hline Residual & -2.9 & -8.8 & 0.6 & 8.9 & -1.8 & -0.9 \\
\hline
\end{tabular}




\section{Panel B: Women}

\begin{tabular}{|c|c|c|c|c|c|c|}
\hline & $\begin{array}{c}\text { Full } \\
\text { Sample }\end{array}$ & $\begin{array}{c}\text { Public } \\
\text { Non-Top } \\
50 \\
\end{array}$ & $\begin{array}{l}\text { Public } \\
\text { Top } 50 \\
\end{array}$ & $\begin{array}{c}\text { Private } \\
\text { Less } \\
\text { Selective } \\
\end{array}$ & $\begin{array}{l}\text { Private } \\
\text { Highly } \\
\text { Selective }\end{array}$ & $\begin{array}{c}\text { Community } \\
\text { College }\end{array}$ \\
\hline NLS72 & 49.2 & 62.4 & 73.1 & 56.5 & 75.6 & 18.6 \\
\hline NELS:88 & 48.5 & 61.8 & 87.7 & 72.6 & 91.4 & 17.5 \\
\hline Total Change & -0.7 & -0.6 & 14.6 & 16.1 & 15.8 & -1.1 \\
\hline Change Due to Observables (X) & -3.6 & -0.1 & 3.3 & 5.0 & 10.6 & -4.2 \\
\hline Change Due to Student Characteristics & 0.3 & 4.0 & 2.1 & 5.9 & 10.5 & -3.8 \\
\hline Math Test Percentiles & -0.7 & 1.2 & 0.7 & 1.9 & 0.5 & -1.7 \\
\hline Other Student Characteristics & 1.0 & 2.8 & 1.4 & 4.0 & 10.0 & -2.1 \\
\hline Change Due to Supply-Side Factors & -3.9 & -4.1 & 1.2 & -0.9 & 0.1 & -0.4 \\
\hline Student-Faculty Ratios & -1.1 & -4.1 & 1.2 & -0.9 & 0.1 & -0.4 \\
\hline Initial School Types & -2.8 & & & & & \\
\hline Residual & 2.9 & -0.5 & 11.3 & 11.1 & 5.2 & 3.1 \\
\hline
\end{tabular}

"Source: Authors' calculations as described in the text from the NLS72 and NELS:88 surveys . NLS72 calculations were made using the fifth follow-up weights included in the survey. Fourth follow-up weights were used for the NELS:88 survey calculations. Only those participating in these follow-ups are included in the regression. School type samples refer to first institution attended. The NLS72 and NELS:88 samples are restricted to those who attend college within two years of cohort high school graduation. Cohort high school graduation is defined as June 1972 for the NLS72 sample and June 1992 for the NELS:88 sample.

${ }^{\mathrm{b}}$ The Change Due to Observables is the difference between the observed NELS:88 completion rate and the simulated NELS:88 completion rate using the distribution of all observables from NLS72. The changes due to math test percentiles, student-faculty ratios and initial school types are the difference between the observed NELS:88 completion rate and the simulated NELS:88 completion rate in which we simulate the completion rate if the each variable were distributed as in the NLS72 survey and all other observables were unchanged. The Change Due to Supply Side Factors is the sum of the changes due to student-faculty ratios and initial school types. We calculate the Change Due to Student Characteristics as the difference between the Change Due to Observables (X) and the Change Due to Supply-Side Factors. The Change Due to Other Student Characteristics is calculated by subtracting the Change Due to Math Test Percentiles from the Change Due to Student Characteristics.

${ }^{\mathrm{c}}$ Data on faculty and enrollment are from the HEGIS/IPEDS surveys from the Department of Education. 
Table 8. State-level Estimates of the Effect of Crowding on Completion Rates, 19401975 Birth Cohorts Observed in the 2000 U.S. Census

\begin{tabular}{ccccccc}
\hline \hline \multicolumn{2}{c}{ Independent Variable: Log of State Birth Cohort Population } \\
\hline $\begin{array}{c}\text { Dependent Variable: } \\
\text { In (BA/Some College) }\end{array}$ & \multicolumn{2}{c}{ Un-weighted } & & \multicolumn{2}{c}{ Weighted } \\
\hline \multirow{2}{*}{ All } & $-0.112^{* *}$ & $-0.165^{* *}$ & & $-0.125^{* *}$ & $-0.185^{* *}$ \\
& $(0.019)$ & $(0.045)$ & & $(0.023)$ & $(0.034)$ \\
& & & & \\
Males & $-0.120^{* *}$ & $-0.230^{* *}$ & & $-0.137^{* *}$ & $-0.191^{* *}$ \\
& $(0.026)$ & $(0.072)$ & & $(0.022)$ & $(0.057)$ \\
& & & & \\
Females & $-0.101^{* *}$ & -0.104 & & $-0.109 * *$ & $-0.177^{* *}$ \\
& $(0.021)$ & $(0.063)$ & & $(0.030)$ & $(0.037)$ \\
& & & & No & Yes \\
\hline
\end{tabular}

${ }^{a}$ Source: 1940-1975 birth cohorts of non-immigrants from the 2000 U.S. Census. Each table entry reflects a separate regression. Each regression includes 1728 state x year cells.

${ }^{\mathrm{b}}$ All regressions are at the state level and include state and birth cohort fixed effects. Alaska, Hawaii, and Washington, DC are excluded from the analysis.

${ }^{c}$ Weighted regressions are weighted with the average cohort size in each state across the 1940-1975 birth cohorts.

${ }^{\mathrm{d}}$ Standard errors are in parentheses and are clustered at the state level.

** Significantly different from 0 at the $5 \%$ level. 
Figure 1. Trends in the Ratio of BA Recipients to Those with Some College or More among 25-Year-Olds

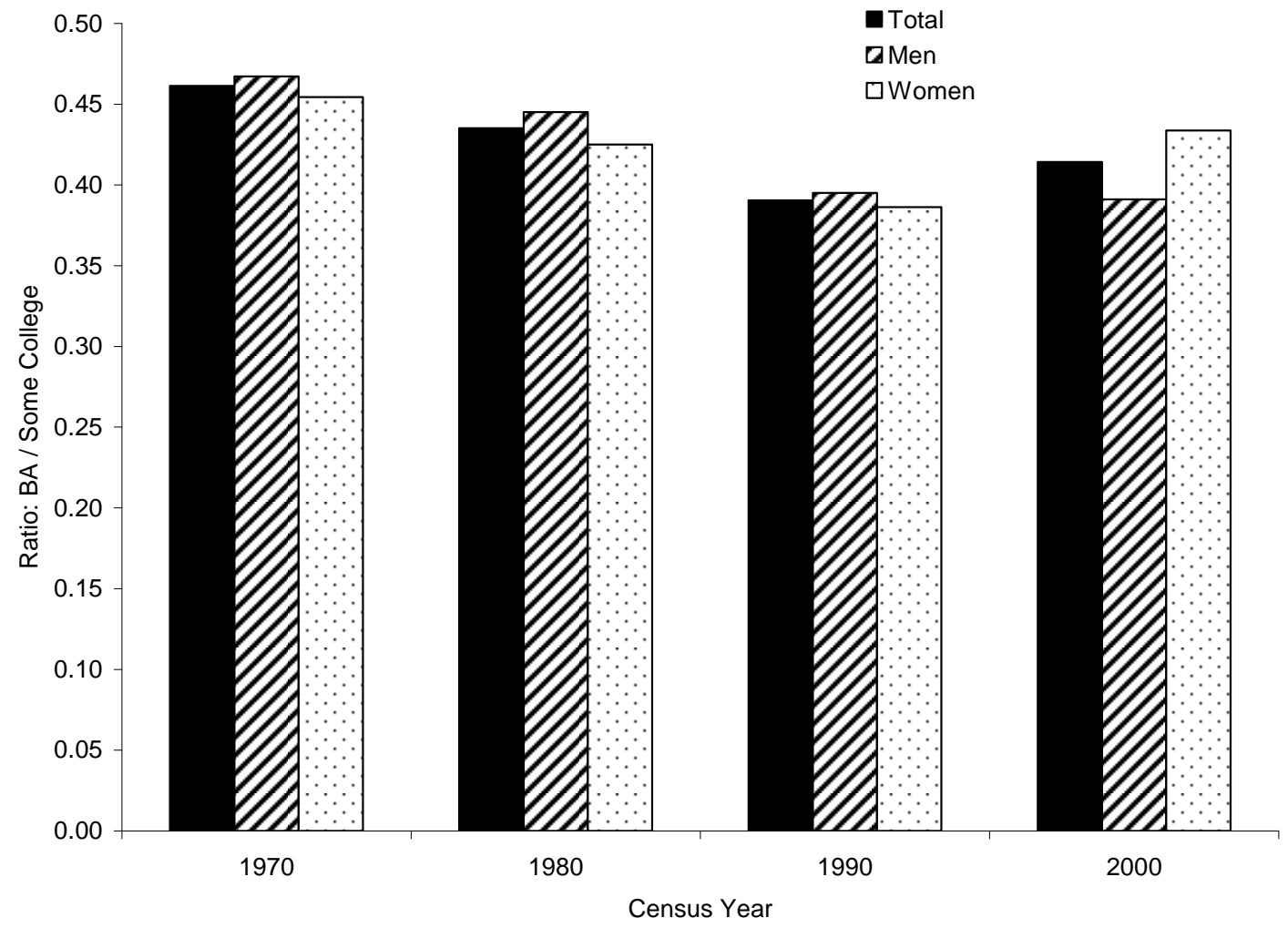

Source: Authors' calculation from Integrated Public Use Microdata Series: Version 3.0 [Machine-readable database http://usa.ipums.org/usa/] Following Jaeger (1997) 74.5 percent of those who attended but did not complete the $13^{\text {th }}$ year of schooling are allocated to the "Some College" category for 1970 and 1980 when educational attainment was reported in terms of completed years of schooling. 
Figure 2. Collegiate Attainment by Pre-Collegiate Achievement

\section{Panel A: College Attendance Conditional on High School Graduation}

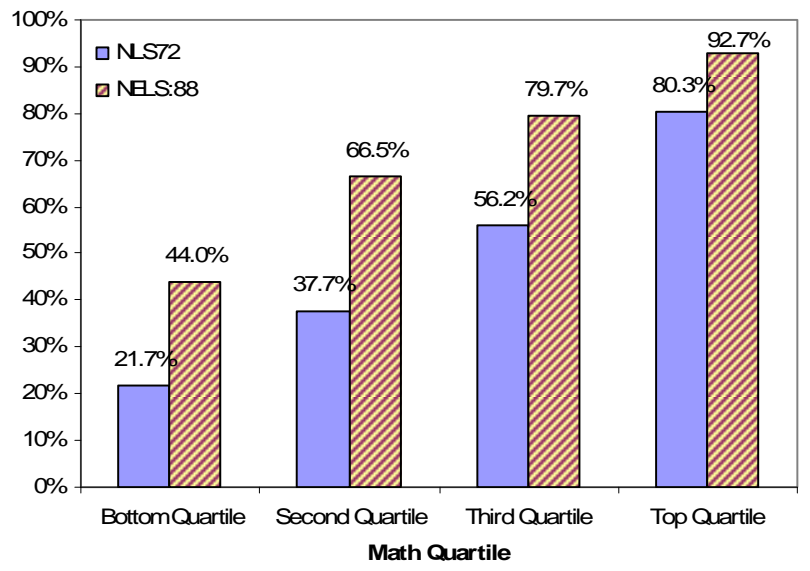

\section{Panel B: College Completion Conditional on High School Graduation}

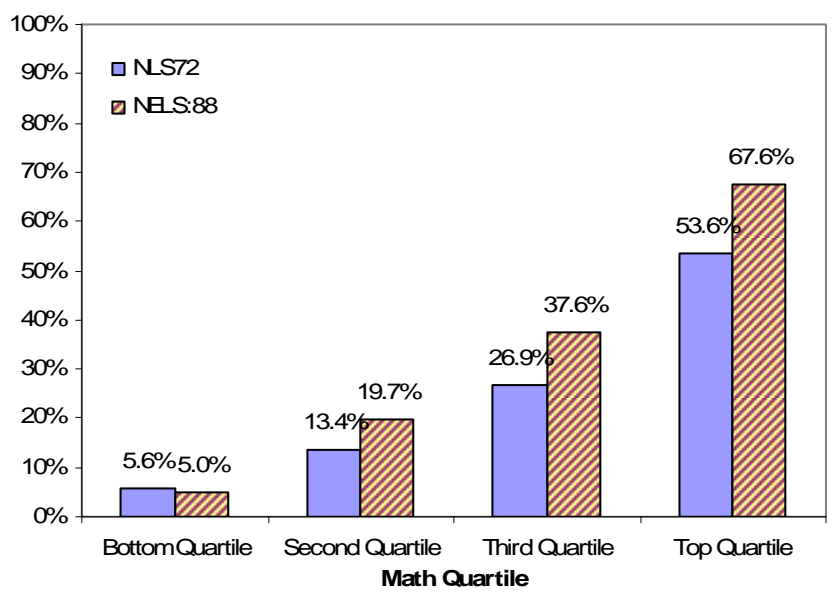

\section{Panel C: College Completion Conditional on College Attendance}

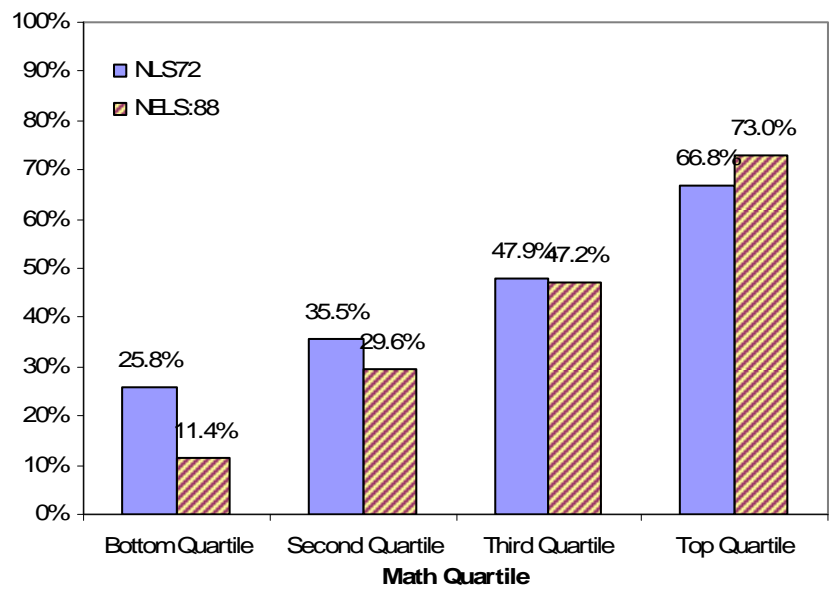

Source: Authors' calculations as described in the text from the NLS72 and NELS:88 surveys. NLS72 calculations were made using the fifth follow-up weights included in the survey. Fourth follow-up weights were used for the NELS:88 survey calculations. Only those participating in these follow-ups are included in the regression. School type samples refer to first institution attended. 
Figure 3. Cumulative Math Test Percentile Distributions by Initial School Type and

\section{Gender}
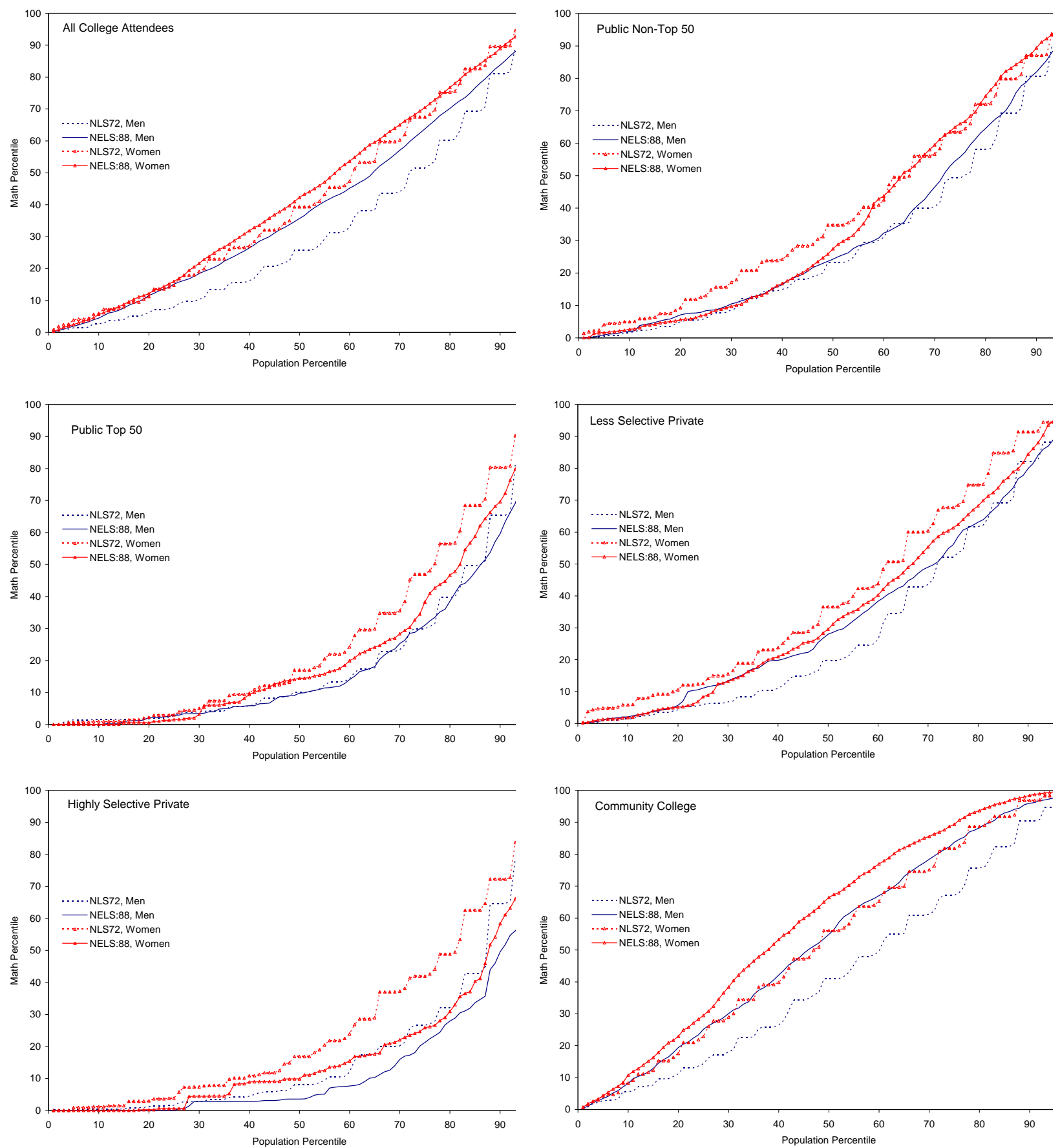

Source: Authors' calculations as described in the text from the NLS72 and NELS:88 surveys. NLS72 calculations were made using the fifth follow-up weights included in the survey. Fourth follow-up weights were used for the NELS:88 survey calculations. Only those participating in these follow-ups are included in the regression. School type samples refer to first institution attended. 
Supplemental Online Appendices

Appendix A: Technical Appendix

\section{NLS72 and NELS:88 Data}

\section{a. Degree Completion}

Degree completion is calculated using National Longitudinal Study of the High School Class of 1972 (NLS72) and the National Educational Longitudinal Study of 1988 (NELS:88) survey responses from the first through fifth follow-ups in NLS72 and the fourth follow-up in NELS:88. The NLS72 study participants were seniors in high school in the spring of 1972. Following the base year interview, participant follow-up surveys were administered in 1973, 1974, 1976, 1979, and 1986 (for a subsample), with questions covering collegiate participation and degree attainment. In addition, detailed high school records and postsecondary transcripts were collected by the Department of Education.

The NELS:88 survey started with students who were in the eighth grade in 1988 (high school class of 1992) and conducted follow-up surveys with participants in 1990, 1992, 1994, and 2000. Similar to the NLS72 survey, NELS:88 contains high school records and collegiate transcripts as well as a host of background information that may be relevant to degree completion.

Degree completion is defined as obtaining a BA within 8 years of cohort high school graduation conditional on beginning college within 2 years of cohort high school graduation. Cohort high school graduation is defined as June 1972 for the NLS72 sample and June 1992 for the NELS:88 sample.

Because the NELS:88 survey is comprised of eighth graders from 1988 and the NLS72 survey follows $12^{\text {th }}$ graders from the class of 1972 , the NELS:88 survey contains more students who graduate high school after their cohort's high school graduation. In our base sample, 1.3\% of respondents in NLS72 and 4.4\% of respondents in NELS:88 finish high school after June of their respective cohort graduation year. However, looking only at eight-year BA recipients, $0.3 \%$ and $0.6 \%$, respectively in NLS72 and NELS:88 did not finish high school on time, and few of these students entered college within 2 years of cohort high school graduation. It is therefore unlikely the larger preponderance of late high school graduates in the NELS:88 survey biases our completion rate calculations.

Table A-1 of this Appendix contains variable names and definitions used to define the sample and to calculate degree completion in both the NLS72 and NELS:88 surveys.

\section{b. School Type and Collegiate Start Dates}

We define enrollment as those who start at an academic institution within two years of cohort high school graduation. Academic institutions are all four-year schools and public twoyear schools. We exclude private two-year schools because they typically are not oriented towards allowing students to obtain a BA post-graduation.

College transcript data and self-reported enrollment records from the first through fourth follow-up surveys for the NLS72 survey and from NCES-aggregated responses in the NELS:88 survey are used to define the type of institution of initial collegiate enrollment. We use the transcript for the first institution post-high school attended by respondents in the transcript files 
to assign first institution attended for most respondents. In the cases in which there are multiple first transcripts from different institutions on the same date, we assign each student to the school at which she took the most credits during the first semester. There are some students who report attending college within two years of their cohort's high school graduation but do not have any transcripts. In NLS72, 6.8\% of the sample reporting attendance do not have transcripts, and in NELS:88, 8.2\% of the sample falls into this category. For these respondents, we use the first institution reported by them in the survey files.

In the NLS72 survey, we begin by determining the year in which a student first enrolls in an academic post-secondary institution, where "academic" is defined as granting at least an associates degree or BA. In each follow-up, students were asked about colleges they attended (up to three) in each year since the previous survey. The first college attended is identified from the entry the first time a student reports attending an academic institution and we record the institutional identifier (FICE code) either directly from transcript files or from the student survey responses about which institution they attended. We then merge institutional-level information that contains public/private status, 2-year/4-year identifiers, and collegiate rankings and classify the respondent's initial institution accordingly.

In the NELS:88 survey, we use a similar methodology to identify each respondent's initial institution. NCES has constructed variables that identify first institution attended in the transcript files (the "ref” variables). We use the transcript-based NCES-constructed institutional identifier ("unitid") code when it is available. For those who report college attendance and the sector of first attendance but are not assigned a transcript-based first institution identifier by NCES, we use the NCES-constructed variables that report individual enrollment histories from the survey data that identify first institution of enrollment ("unitid") and first institution type (“f4efsect”).

For students with post-secondary experience preceding high school graduation, we use the first start date and institution after high school graduation taken from the post-secondary transcript files. For all other students in the NELS:88 survey, first start date is identified by f4efmy, which is the NCES-constructed date of first post-secondary attendance.

A list of the top-50 public schools from the 2005 U.S. News and World Report rankings as well as the top-65 private schools and the top-50 liberal arts colleges plus the United States Armed Services Academies, which constitute the highly selective private schools, is shown is shown in Table A-2.

\section{c. Background Characteristics}

\section{i. Math Tests}

In both surveys, tests of academic achievement were administered to students in the senior year. The NLS72 exam was administered as a 69-minute test book with sections on vocabulary, picture numbers (associative memory), reading, letter groups, mathematics, and mosaic comparisons. Each section was 15 minutes (except for the mosaic comparison, which was 9 minutes). The math test included 25 items and contained only quantitative comparisons in order to measure basic quantitative competence. We use the reported scaled math score (scmatsc) test score measure in NLS72.

The NELS:88 cognitive test batteries were administered in each of the first three waves, with sections on reading, math, science and social studies. The tests were 85 minutes and consisted of 116 questions, 40 of which were on math and 21 of which were on reading 
comprehension. Unlike the NLS72 exams, the NELS:88 tests covered more material and tested more skills. The math exam consisted of word problems, graphs, equations, quantitative comparisons, and geometric figures. Further, because the NELS:88 tests were given in subsequent waves, students were given harder or easier tests in the first and second follow-ups depending on their scores in the previous wave to guard against floor and ceiling effects. We use the math IRT theta score (f22xmth) from the second follow-up as the base measure of test scores. These scores are psychometric evaluation scores of each student's ability that account for the difficulty of the exam.

Because the tests in NLS72 and NELS:88 covered different subject matter, were of different lengths, and were graded on different scales, the scores are not directly comparable across surveys. Instead, we construct the percentile of the score distribution for each survey among all high school graduates. The comparison of students in the same test percentile across surveys is based on the assumption overall achievement did not change over this time period. This assumption is supported by the observation that there is little change in the overall level of test scores on the nationally-representative NAEP over our period of observation. Similarly, examination of time trends in standard college entrance exams such as the SAT provides little support for the proposition that achievement declined appreciable over the interval. For the SAT, the ratio of test takers to high school graduates increased from 33\% to 42\%, while mean math scores declined from 509 to 501 over the 1972 to 1992 interval (Digest of Education Statistics, 2005, Table 129).

In the NLS72 survey, we use high school GPA as an imputation variable in order to measure pre-collegiate academic ability for students with missing test scores. The GPA measure we use is "imptaver" from the NLS72 survey. In the multiple imputation of missing variables in the NELS:88 survey, we use IRT theta test scores from the first follow-up for math (f12xmth) and from the base year for math (by2xmth). The IRT theta scores are scaled to a common metric across years by NCES. The imputed math test scores from the senior year in each survey are used to construct the test percentiles used in the main analysis.

\section{ii. Parental Education}

We obtain student reported measures of father's and mother's education separately. In the NLS72 survey, we have three different measures of this variable. For mother's education, we use the variables cmoed, bq90b, and fq78b. For father's education, we use the variables cfaed, bq90a, and fq78a. If there are disagreements across measures, fq78b and fq78a take precedence.

In the NELS:88 survey, we also use student reports of father's education (bys34a) and mother's education (bys34b). For the multiple imputation model, we include parent self-reports of their own education from the base year and second follow-up parental surveys. In the base year parent survey, we combine information on whether the respondent and his/her spouse is the father or mother (byp1a1 and byp1a2) with reported self (byp30) and spouse (byp31) educational attainment. A similar methodology is used for the second-follow up parent survey, using f2p1a and $\mathrm{f} 2 \mathrm{p} 1 \mathrm{~b}$ to identify the gender of the respondent and the spouse, respectively, and f2p101a and f2p101b to identify educational attainment of the respondent and the spouse, respectively. The base year and second follow-up parental education information is aggregated into two variables, father's education and mother's education, used in the multiple imputation model.

\section{iii. Parental Income Levels}


The parental income variables are bq93 for NLS72 and f2p74 for NELS:88. The former is reported by the student while the latter is reported by the parents. Unfortunately, NLS72 does not contain a parent-reported measure and the NELS:88 survey does not contain a studentreported measure, so these variables are the most closely aligned parental income measures across the two surveys.

Rather than asking directly for parental income levels, the NELS:88 and NLS72 surveys ask for income ranges from respondents. Because we are interested in measuring parents' ability to finance college, the variable of interest is the real income level, not one's place in the income distribution. We thus align the income blocks across the two surveys using the CPI. In NLS72, the measured income groups we construct are less than $\$ 3000$, $\$ 3000-\$ 6000, \$ 6000-\$ 7500$, $\$ 7500-\$ 10500$, $\$ 10500-\$ 15000$, and greater than $\$ 15000$. In NELS:88, the corresponding real income blocks we create are less than $\$ 10000$, $\$ 10000-\$ 20000$, $\$ 20000-\$ 25000$, $\$ 25000$ $\$ 35000, \$ 35000-\$ 50000$, and greater than $\$ 50000$. Across surveys, the six income groups are comparable in real terms.

\section{iv. Race}

Race is measured in the NLS72 survey using "crace" and "race86." The latter is used if the former is blank due to non-response. In the NELS:88 survey, race is measured using the "race" variable available in the data files.

\section{Procedures to Handle Missing Data}

\section{d. Multiple Imputation}

There is a considerable amount of missing data in the NLS72 and NELS:88 surveys. Table A-3 of this Appendix presents the number of unweighted missing observations by variable and survey. These observations are not missing completely at random; respondents who have no math test scores are less likely to finish college conditional on starting.

Casewise deletion of missing observations will therefore cause a bias in the calculation of the base trends we are seeking to explain in this analysis. To deal with this problem, we use the multiple imputation by chained equation (MICE) algorithm developed by Van Buuren, Boshuizen, and Knook (1999) that is implemented through the STATA module "ICE" (see Royston (2004) for a detailed discussion of ICE).

MICE is implemented by first defining the set of predictor variables $\left(\mathrm{x}_{1} \ldots \mathrm{x}_{\mathrm{k}}\right)$ and the set of variables with missing values to be imputed: math test scores, father's education, mother's education, and parental income levels $\left(\mathrm{y}_{1} \ldots \mathrm{y}_{5}\right)$. The MICE algorithm implemented by ICE first randomly fills in all missing values from the posterior distribution of each variable. Then, for each variable with missing data, $\mathrm{y}_{\mathrm{i}}$, STATA runs a regression (or ordered logit) of $\mathrm{y}_{\mathrm{i}}$ on $\mathrm{y}_{\sim \mathrm{i}}$ and $\mathrm{x}_{1} \ldots \mathrm{x}_{\mathrm{k}}$ and calculates expected values from these regressions for all missing data points. The expected values then replace the randomly assigned values for the missing data points. A sequence of regressions for each $\mathrm{y}_{\mathrm{i}}$ is a cycle, and this process is repeated for 10 cycles, replacing the missing values with the new expected values from each regression in each cycle. The imputed values after 10 cycles constitute one imputed data set, and this process is repeated five different times to generate five imputed data sets.

There are two important specifications in implementing MICE: determination of the predictor variables and determination of the imputation models. Because of the different 
structure of the two surveys, different variables are used in the imputation procedure across surveys. In both surveys, we include dummy variables for cumulative time to degree from four to eight years, dummy variables for initial school type, interactions between these variables, an indicator for college attendance within two years of cohort high school graduation, as well as race and gender indicators.

For imputations with the NLS72 sample, we include a measure of high school GPA in order to proxy for unobserved ability among those without test score information. Due to the structure of the NELS:88 survey, there is more background information with which to impute missing data. We use $8^{\text {th }}$ and $10^{\text {th }}$ grade math test scores, parental reports of their education from the base year and second follow-up parent surveys, and parental reports of their income level from the base year parent survey. The definitions of the variables used in the imputation models are discussed in the preceding section.

Because the math test scores are continuous variables, we use OLS regressions to impute these variables. Mother's and father's education and income, however, are categorical variables. Because of the ordered nature of these variables, we use ordered logits to impute the missing values of these variables. While these model choices are reasonably arbitrary, they are only used to draw ranges of plausible estimates of missing data.

The multiple imputation procedure creates five different data sets, each with different imputed values for the missing observations. All reported statistics and results in our analysis are averages across data sets. In other words, we conduct each analysis separately for each data set and average the final result. The average of final results is what is reported in the tables and figures in the paper. For the completion logit estimates in Table 5, we use the "micombine" command in STATA that is designed to estimate coefficients and standard errors from multiply imputed data sets. The coefficient estimates represent the simple arithmetic mean across the five coefficients from each imputed data set for each variable. Standard error estimation in this context is more complex. See Carlin et al. (2003) for a complete description of how standard errors are calculated.

\section{e. Dropped Observations and Missing Transcript Data}

The base sample in this analysis consists of all respondents who graduate high school and attend college within two years of their cohort's high school graduation. We further restrict the sample to exclude those whose only enrollment over this time period is at a private two-year institution as these schools are predominantly professional without a BA track. Table A-4 presents information on the number of observations that are dropped by survey and the reason for dropping the observation. For example, 168 respondents are dropped because they are not high school graduates in NLS72 whereas 720 are dropped in NELS:88 for this reason. The apparently higher dropout rate in NELS:88 is because the universe of students are all those enrolled in the $8^{\text {th }}$ grade in 1988, whereas the universe in NLS72 are all those enrolled in $12^{\text {th }}$ grade in 1972.

In the NLS72 survey, 63 observations are dropped because they report attending college but provide no information on either the type of institution or the date they first began attending this institution, and in NELS:88, 50 respondents do not provide this information. In addition, 200 observations were dropped because they were not in all four waves of the NELS:88 survey. In other words, they have a sample weight of zero. 
Of potential concern in constructing our sample is the exclusion of those beginning college more than two years post-high school cohort graduation. We exclude these observations because we are interested in the truncated, eight-year completion rate. These statistics have a different interpretation for a student who began college directly after high school than for a student who began college, for instance, five years after high school. In NLS72, 889 respondents attend college more than 2 years after their cohort's high school graduation, and in NELS:88, 970 do so. Given the similarity of these numbers, shifts in when students began attending college cannot account for the trends in completion rates reported in the main text.

\section{Counterfactual Simulation Procedure}

The counterfactual math test scores, student-faculty ratios and initial school types are computed using a matching algorithm that holds relative rank constant. The goal of this procedure is to generate a counterfactual of the variable $X$ on the NELS:88 sample that has the same distribution as the variable in the NLS72 sample. To construct this counterfactual, we first expand both data sets based on the analysis sample weights and then balance the two surveys by randomly deleting observations from the survey with more weighted observations. The weightexpanded samples then have the same number of observations in each survey. We then use the psmatch2 program in STATA to match each NELS:88 respondent to a NLS72 respondent on the variable $X$, using single nearest neighbor matching without replacement. For each NELS:88 respondent, we assign a counterfactual value of $X$ that is equal to the value from the unique match. This matching method creates a counterfactual distribution of $X$ in the NELS:88 sample that has the same mean as in the NLS72 sample and has a distribution that holds relative rankorder constant across the surveys. Using single nearest neighbor matching on $X$ without replacement with psmatch2 ensures that we are finding a unique match for each NELS:88 respondent and that we are breaking ties randomly. Finally, we collapse the data back down to the individual level to conduct our analyses.

Because the math test percentiles we use are multiply imputed, we perform this procedure separately for each imputed data set. However, the imputations are done separately by survey, so it is not correct to match similarly numbered imputations with each other across cohorts. Instead, for each imputation in NELS:88, we perform our matching algorithm separately for each imputation in NLS72 and take the average counterfactual math test percentile across NLS72 imputations for each NELS:88 imputation. This procedure requires us to perform the matching algorithm 25 times when we simulate counterfactual math test percentiles.

When we simulate counterfactual student-faculty ratios and initial school types, we only have to conduct the matching algorithm once because none of the data are imputed. But, for student-faculty ratios, there are a number of missing observations. To handle this difficulty, we treat missing status as a fixed attribute and perform the matching only for observations with nonmissing student-faculty ratio values. For those with missing student-faculty ratios, they are assumed to have missing data both in the observed and counterfactual completion rate calculations.

With test score percentiles and student-teacher ratios, establishing rank-order is straightforward as these variables are cardinal. For initial school type, however, how to rankorder the samples is less clear. For the matching procedure, we order school types in ascending order from least to most selective. Thus, school type 1 is community colleges, followed by nontop 50 public universities, less selective private universities, top 50 public schools, and finally 
highly selective private universities. The logic behind this ordering is that we are assigning students in our counterfactual simulations to sectors that are most similar to their observed sector; we are not assigning, for example, students in community colleges to the highly selective private sector when finding counterfactual school types. This ordering creates conservative estimates of the effect of school type shifts on completion rates because we are minimizing the quality increases for each student associated with the shift across sectors that has occurred over time.

\section{$\underline{\text { References }}$}

Carlin, John B., Ning Li, Philip Greenwood, and Carolyn Coffey. 2003. “Tools for Analyzing Multiple Imputed Datasets.” Stata Journal, 3(3): 226-244.

Royston, Patrick. 2004. “Multiple Imputation of Missing Values.” Stata Journal, 4(3): 227-241.

Van Buuren, Stef, Hendriek C. Boshuizen, and Dick L. Knook. 1999. "Multiple Imputation of Missing Blood Pressure Covariates in Survival Analysis.” Statistics in Medicine, 18(6): 681-694. 
Table A-1. Variable Names and Definitions for Calculation of Completion Rates in NLS72 and NELS:88

\begin{tabular}{|c|c|c|}
\hline \multicolumn{3}{|c|}{ Panel A: NLS72 } \\
\hline Variable Name & Variable Definition & Follow Up \\
\hline Fq2 & High school completion dummy & 2 \\
\hline Edatt86 & Educational attainment as of 1986 & $1-5$ \\
\hline $\mathrm{Fq3b}$ & High school graduation year & 2 \\
\hline $\mathrm{Fq3a}$ & High school graduation month & 2 \\
\hline Tq48ea & BA completion dummy as of $10 / 1 / 1976$ & 3 \\
\hline Tq48eb & Month BA received as of third follow-up & 3 \\
\hline Tq48ec & Year BA received as of third follow-up & 4 \\
\hline Ft76ea & BA completion as of fourth follow-up & 4 \\
\hline Ft76eb & Month BA received as of fourth follow-up & 4 \\
\hline Ft76ec & Year BA received as of fourth follow-up & 5 \\
\hline Fi19b1ey - Fi19b4ey & $\begin{array}{l}\text { Year ended most recent school attended, first } \\
\text { through fourth time }\end{array}$ & 5 \\
\hline Fi19b1em-Fi19b4em & $\begin{array}{l}\text { Month ended most recent school attended, first } \\
\text { through fourth time }\end{array}$ & 5 \\
\hline Fi19h & Course of study in most recent school attended & 5 \\
\hline Fi19i & $\begin{array}{l}\text { Completed requirements in most recent school } \\
\text { attended }\end{array}$ & 5 \\
\hline Fi20b1ey-Fi20b4ey & $\begin{array}{l}\text { Year ended } 2^{\text {nd }} \text { most recent school attended, first } \\
\text { through fourth time }\end{array}$ & 5 \\
\hline Fi20b1em-Fi20b4em & $\begin{array}{l}\text { Month ended } 2^{\text {nd }} \text { most recent school attended, first } \\
\text { through fourth time }\end{array}$ & 5 \\
\hline Fi19h & Course of study in $2^{\text {nd }}$ most recent school attended & 5 \\
\hline Fi19i & $\begin{array}{l}\text { Completed requirements in } 2^{\text {nd }} \text { most recent school } \\
\text { attended }\end{array}$ & 5 \\
\hline \multicolumn{3}{|c|}{ Panel B: NELS:88 } \\
\hline Variable Name & Variable Definition & Follow Up \\
\hline F4hsgradt & High school graduation date & 4 \\
\hline F4ed1 & Degree receipt date-first degree received & 4 \\
\hline F4edgr1 & Degree type received-first degree & 4 \\
\hline F4ed2 & Degree receipt date-second degree received & 4 \\
\hline F4edgr2 & Degree type received-second degree & 4 \\
\hline F4ed3 & Degree receipt date-third degree received & 4 \\
\hline F4edgr3 & Degree type received-third degree & 4 \\
\hline F4ed4 & Degree receipt date-fourth degree received & 4 \\
\hline F4edgr4 & Degree type received-fourth degree & 4 \\
\hline F4ed5 & Degree receipt date-fifth degree received & 4 \\
\hline F4edgr5 & Degree type received-fifth degree & 4 \\
\hline F4ed6 & Degree receipt date-sixth degree received & 4 \\
\hline F4edgr6 & Degree type received-sixth degree & 4 \\
\hline
\end{tabular}


Table A-2. Top-50 Public Schools, Top-65 Private Schools and Top-50 Liberal Arts Colleges from the 2005 U.S. News and World Report Rankings

\begin{tabular}{|c|c|c|c|}
\hline \multirow[b]{2}{*}{ Top-50 Public Schools } & \multicolumn{3}{|c|}{ Highly Selective Private Schools } \\
\hline & \multicolumn{2}{|c|}{ Top-65 Private Schools } & Top-50 Liberal Arts \\
\hline University of California - Berkeley & Harvard University & University of Tulsa & Amherst College \\
\hline University of Virginia & Princeton University & Texas Christian University & Williams College \\
\hline University of Michigan - Ann Arbor & Yale University & University of Dayton & Swarthmore College \\
\hline University of California - Los Angeles & University of Pennsylvania & Drexel University & Wellesley College \\
\hline University of North Carolina - Chapel Hill & Duke University & Illinois Institute of Technology & Carleton College \\
\hline College of William and Mary & MIT & University of San Diego & Middlebury College \\
\hline University of Wisconsin - Madison & Stanford University & Catholic University & Pomona College \\
\hline University of California - San Diego & California Institute of Tech. & Loyola University & Bowdoin College \\
\hline University of Illinois & Columbia University & Univ. of San Francisco & Davidson College \\
\hline Georgia Institute of Technology & Dartmouth College & University of the Pacific & Haverford College \\
\hline University of California - Davis & Northwestern University & New School & Claremont-McKenna \\
\hline University of California - Irvine & Washington Univ. of St. Louis & Northeastern University & Wesleyan University \\
\hline University of California - Santa Barbara & Brown University & Seton Hall University & Grinell College \\
\hline University of Texas - Austin & Cornell University & University of St. Thomas & Vassar College \\
\hline University of Washington & Johns Hopkins University & & Harvey Mudd College \\
\hline Pennsylvania State University & University of Chicago & & Washington and Lee \\
\hline University of Florida & Rice University & & Smith College \\
\hline University of Maryland - College Park & Notre Dame University & & Hamilton College \\
\hline Rutgers University - New Brunswick & Vanderbilt University & & Colgate University \\
\hline University of Georgia & Emory University & & Oberlin College \\
\hline University of Iowa & Carnegie Mellon University & & Colby College \\
\hline Miami University (Ohio) & Georgetown University & & Bates College \\
\hline Ohio State University & Wake Forest University & & Bryn Mawr College \\
\hline Purdue University & Tufts University & & Colorado College \\
\hline Texas A\&M - College Station & Univ. of Southern California & & Macalester College \\
\hline University of Connecticut & Brandeis University & & Scripps College \\
\hline University of Delaware & New York University & & Mt. Holyoke College \\
\hline University of Minnesota - Twin Cities & Case Western Reserve & & Barnard College \\
\hline University of Pittsburgh & Boston College & & Bucknell University \\
\hline Indiana University & Lehigh University & & Kenyon College \\
\hline Michigan State University & Univ. of Rochester & & College of the Holy Cross \\
\hline Clemson University & Tulane University & & Trinity College \\
\hline SUNY at Binghamton & Rensselaer Polytechnic & & Lafayette College \\
\hline University of California - Santa Cruz & Yeshiva University & & Occidental College \\
\hline University of Colorado - Boulder & George Washington Univ. & & Bard College \\
\hline Virginia Tech. & Pepperdine University & & Furman University \\
\hline University of California - Riverside & Syracuse University & & Whitman College \\
\hline Iowa State University & Worcester Polytechnic & & Union College \\
\hline North Carolina State University & Boston University & & Franklin and Marshall \\
\hline University of Alabama & University of Miami & & Sewanee College \\
\hline University of Missouri - Columbia & Fordham University & & University of Richmond \\
\hline Auburn University & Southern Methodist Univ. & & Connecticut College \\
\hline University of Kansas & Brigham Young University & & Centre College \\
\hline University of Tennessee - Knoxville & Clark University & & Dickinson College \\
\hline University of Vermont & Stevens Inst. of Technology & & Skidmore College \\
\hline Ohio University & St. Louis University & & Gettysburg College \\
\hline University of Arizona & Baylor University & & Pitzer College \\
\hline University of Massachusetts - Amherst & American University & & DePauw University \\
\hline University of Nebraska - Lincoln & Howard University & & Rhodes College \\
\hline University of New Hampshire & Marquette University & & Reed College \\
\hline
\end{tabular}

Source: 2005 U.S. News and World Report Rankings of colleges and universities in the United States. Schools are listed in the order they appear in the U.S. News and World Report ranking. The rankings include many ties, in which case schools are listed alphabetically within rank. This table lists schools within rank in the same manner. The highly selective private school category also includes the four U.S. Armed Services Academies: U.S. Naval Academy, U.S. Air Force Academy, U.S. Military Academy at West Point and U.S. Coast Guard Academy. 
Table A-3. Number of Imputed Observations by Survey and Variable

(Unweighted)

\begin{tabular}{|c|c|c|}
\hline & \multicolumn{2}{|c|}{$\begin{array}{l}\text { Number of Imputed } \\
\text { Observations }\end{array}$} \\
\hline Variable & NLS72 & NELS:88 \\
\hline Math Test Score & 1,961 & 1,560 \\
\hline Mother's Education & 46 & 1,200 \\
\hline Father’s Education & 46 & 1,410 \\
\hline Parent Income & 1,634 & 1,160 \\
\hline Total & 3,687 & 5,330 \\
\hline
\end{tabular}

on counts include only those respondents who enroll in college within two years of cohort high school graduation at a four-year institution or a non-private two-year college. Per the restricted data license agreement with the National Center for Education Statistics, all unweighted NELS:88 sample sizes are rounded to the nearest 10 .

Table A-4. Number of Dropped Observations by Category (Un-weighted)

\begin{tabular}{|c|c|c|}
\hline \multicolumn{3}{|c|}{ NLS72 } \\
\hline Sample Change & $\begin{array}{c}\text { Dropped } \\
\text { Observations }\end{array}$ & $\begin{array}{c}\text { Remaining } \\
\text { Observations }\end{array}$ \\
\hline Original Base $-5^{\text {th }}$ Follow Up Sample & & 12841 \\
\hline High School Dropouts & 168 & 12673 \\
\hline Missing Initial School Information & 63 & 12610 \\
\hline Never Attended College & 4503 & 8107 \\
\hline Time between HS and College $>2$ Years & 889 & 7218 \\
\hline \multicolumn{3}{|c|}{ NELS:88 } \\
\hline Sample Change & $\begin{array}{c}\text { Dropped } \\
\text { Observations }\end{array}$ & $\begin{array}{c}\text { Remaining } \\
\text { Observations }\end{array}$ \\
\hline Original Base- $4^{\text {th }}$ Follow Up Sample & & 12140 \\
\hline High School Dropouts & 720 & 11420 \\
\hline Observations not in all 4 Waves & 200 & 11220 \\
\hline Missing Initial School Information & 50 & 11170 \\
\hline Never Attended College & 1920 & 9250 \\
\hline Time between HS and College $>2$ Years & 970 & 8280 \\
\hline
\end{tabular}

Per the restricted data license agreement with the National Center for Education Statistics, all unweighted NELS:88 sample sizes are rounded to the nearest 10. 
Table B-1. Decompositions Using Average Derivatives From Logit Models of College Completion in the NELS:88 Survey by Type of Institution

\begin{tabular}{|c|c|c|c|c|c|c|}
\hline & $\begin{array}{c}\text { Full } \\
\text { Sample }\end{array}$ & $\begin{array}{c}\text { Public } \\
\text { Non-Top } \\
50 \\
\end{array}$ & $\begin{array}{l}\text { Public } \\
\text { Top } 50 \\
\end{array}$ & $\begin{array}{c}\text { Private } \\
\text { Less } \\
\text { Selective }\end{array}$ & $\begin{array}{c}\text { Private } \\
\text { Highly } \\
\text { Selective }\end{array}$ & $\begin{array}{c}\text { Community } \\
\text { College }\end{array}$ \\
\hline NLS72 & 50.5 & 61.8 & 73.5 & 58.2 & 80.1 & 20.2 \\
\hline NELS:88 & 45.9 & 56.9 & 82.5 & 70.5 & 90.3 & 17.6 \\
\hline Total Change & -4.6 & -4.9 & 9.0 & 12.3 & 10.3 & -2.5 \\
\hline Change Due to Observables (X) & -4.0 & -1.7 & 3.4 & 3.0 & 6.5 & -3.5 \\
\hline Change Due to Student Characteristics & -0.4 & 2.1 & 2.8 & 3.6 & 6.3 & -3.0 \\
\hline Math Test Percentiles & -1.6 & 0.1 & 1.0 & 0.2 & 0.4 & -2.6 \\
\hline Other Student Characteristics & 1.2 & 2.0 & 1.8 & 3.4 & 5.9 & -0.4 \\
\hline Change Due to Supply-Side Factors & -3.6 & -3.8 & 0.6 & -0.6 & 0.2 & -0.5 \\
\hline Student-Faculty Ratios & -1.2 & -3.8 & 0.6 & -0.6 & 0.2 & -0.5 \\
\hline Initial School Types & -2.4 & & & & & \\
\hline Residual & -0.6 & -3.2 & 5.6 & 9.3 & 3.8 & 1.0 \\
\hline
\end{tabular}

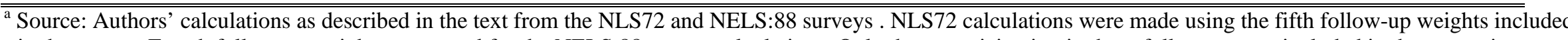
in the survey. Fourth follow-up weights were used for the NELS:88 survey calculations. Only those participating in these follow-ups are included in the regression.

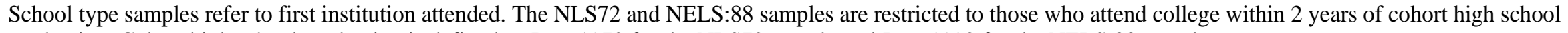
graduation. Cohort high school graduation is defined as June 1972 for the NLS72 sample and June 1992 for the NELS:88 sample.

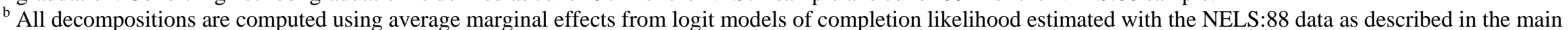
text. Simulated changes are calculated by multiplying the average marginal effect for a given variable by the observed change in means across surveys.

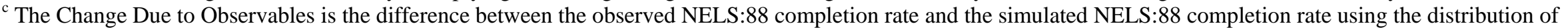

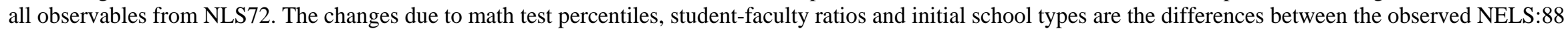

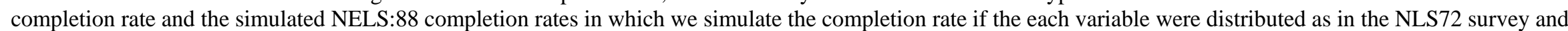
all other observables were unchanged. The Change Due to Supply Side Factors is the sum of the changes due to student-faculty ratios and initial school types. We calculate the Change Due to Student Characteristics as the difference between the Change Due to Observables (X) and the Change Due to Supply-Side Factors. The Change Due to Other Student Characteristics is calculated by subtracting the Change Due to Math Test Percentiles from the Change Due to Student Characteristics.

${ }^{\mathrm{d}}$ Data on faculty and enrollment are from the HEGIS/IPEDS surveys from the Department of Education.
} 
Table B-2. Decompositions Using Average Derivatives From Logit Models of College Completion in the NELS:88 Survey by Type of Institution and Gender

\begin{tabular}{|c|c|c|c|c|c|c|}
\hline \multicolumn{7}{|c|}{ Panel A: Men } \\
\hline & $\begin{array}{c}\text { Full } \\
\text { Sample }\end{array}$ & $\begin{array}{c}\text { Public } \\
\text { Non-Top } \\
50 \\
\end{array}$ & $\begin{array}{l}\text { Public } \\
\text { Top } 50 \\
\end{array}$ & $\begin{array}{c}\text { Private } \\
\text { Less } \\
\text { Selective }\end{array}$ & $\begin{array}{l}\text { Private } \\
\text { Highly } \\
\text { Selective }\end{array}$ & $\begin{array}{c}\text { Community } \\
\text { College }\end{array}$ \\
\hline NLS72 & 51.7 & 61.2 & 73.8 & 59.9 & 82.7 & 21.6 \\
\hline NELS:88 & 43.2 & 51.6 & 77.5 & 67.7 & 89.2 & 17.7 \\
\hline Total Change & -8.5 & -9.6 & 3.7 & 7.8 & 6.5 & -3.9 \\
\hline Change Due to Observables (X) & -5.4 & -2.1 & 1.9 & 1.1 & 7.1 & -3.6 \\
\hline Change Due to Student Characteristics & -1.2 & 1.5 & 1.3 & 1.5 & 6.6 & -3.0 \\
\hline Math Test Percentiles & -2.5 & -0.7 & 0.6 & -1.9 & 0.4 & -3.1 \\
\hline Other Student Characteristics & 1.3 & 2.2 & 0.7 & 3.4 & 6.2 & 0.1 \\
\hline Change Due to Supply-Side Factors & -4.2 & -3.6 & 0.6 & -0.4 & 0.5 & -0.6 \\
\hline Student-Faculty Ratios & -1.3 & -3.6 & 0.6 & -0.4 & 0.5 & -0.6 \\
\hline Initial School Types & -2.9 & & & & & \\
\hline Residual & -3.1 & -7.5 & 1.8 & 6.7 & -0.6 & -0.3 \\
\hline
\end{tabular}




\section{Panel B: Women}

\begin{tabular}{|c|c|c|c|c|c|c|}
\hline & $\begin{array}{c}\text { Full } \\
\text { Sample }\end{array}$ & $\begin{array}{c}\text { Public } \\
\text { Non-Top } \\
50\end{array}$ & $\begin{array}{l}\text { Public } \\
\text { Top } 50\end{array}$ & $\begin{array}{c}\text { Private } \\
\text { Less } \\
\text { Selective }\end{array}$ & $\begin{array}{c}\text { Private } \\
\text { Highly } \\
\text { Selective }\end{array}$ & $\begin{array}{c}\text { Community } \\
\text { College }\end{array}$ \\
\hline NLS72 & 49.2 & 62.4 & 73.1 & 56.5 & 75.6 & 18.6 \\
\hline NELS:88 & 48.5 & 61.8 & 87.7 & 72.6 & 91.4 & 17.5 \\
\hline Total Change & -0.8 & -0.6 & 14.6 & 15.9 & 15.8 & -1.1 \\
\hline Change Due to Observables (X) & -2.8 & -1.4 & 3.5 & 4.3 & 5.3 & -3.5 \\
\hline Change Due to Student Characteristics & 0.2 & 2.4 & 2.9 & 5.1 & 5.3 & -3.0 \\
\hline Math Test Percentiles & -0.6 & 1.0 & 1.4 & 2.1 & 0.5 & -2.0 \\
\hline Other Student Characteristics & 0.8 & 1.4 & 1.5 & 3.0 & 4.8 & -1.0 \\
\hline Change Due to Supply-Side Factors & -3.0 & -3.8 & 0.6 & -0.8 & 0.0 & -0.5 \\
\hline Student-Faculty Ratios & -1.2 & -3.8 & 0.6 & -0.8 & 0.0 & -0.5 \\
\hline Initial School Types & -1.8 & & & & & \\
\hline Residual & 2.0 & 0.8 & 11.1 & 11.6 & 10.5 & 2.4 \\
\hline
\end{tabular}

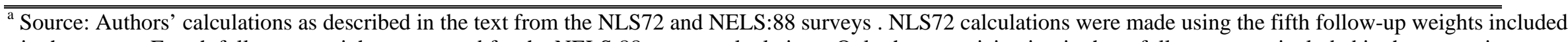
in the survey. Fourth follow-up weights were used for the NELS:88 survey calculations. Only those participating in these follow-ups are included in the regression.

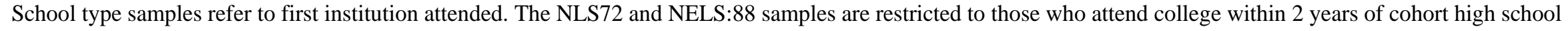
graduation. Cohort high school graduation is defined as June 1972 for the NLS72 sample and June 1992 for the NELS:88 sample.

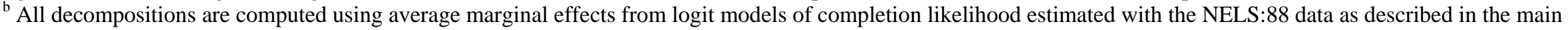
text. Simulated changes are calculated by multiplying the average marginal effect for a given variable by the observed change in means across surveys.

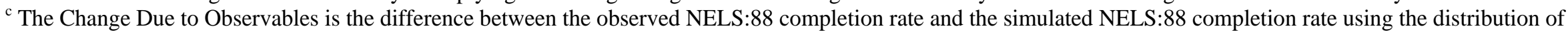

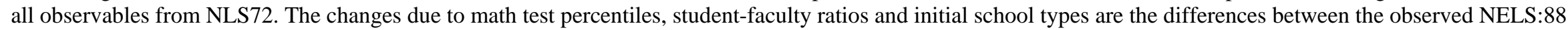

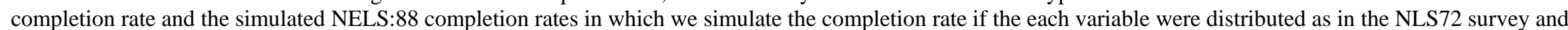
all other observables were unchanged. The Change Due to Supply Side Factors is the sum of the changes due to student-faculty ratios and initial school types. We calculate the Change Due to Student Characteristics as the difference between the Change Due to Observables (X) and the Change Due to Supply-Side Factors. The Change Due to Other Student Characteristics is calculated by subtracting the Change Due to Math Test Percentiles from the Change Due to Student Characteristics.

${ }^{\mathrm{d}}$ Data on faculty and enrollment are from the HEGIS/IPEDS surveys from the Department of Education. 
Table B-3. Oaxaca-Blinder Decompositions based on NELS:88 Estimates of College Completion by Type of Institution

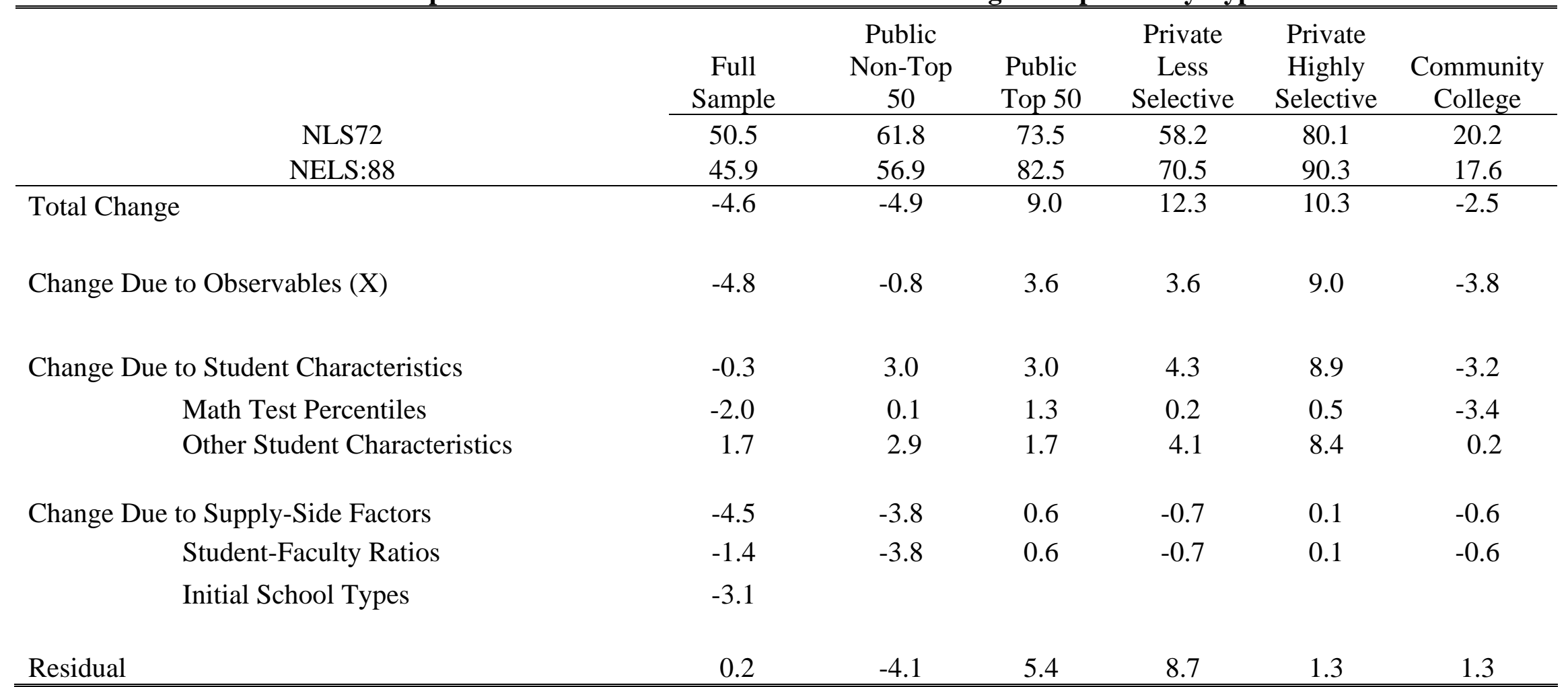

\footnotetext{
${ }^{a}$ Source: Authors' calculations as described in the text from the NLS72 and NELS:88 surveys . NLS72 calculations were made using the fifth follow-up weights included in the survey. Fourth follow-up weights were used for the NELS:88 survey calculations. Only those participating in these follow-ups are included in the regression. School type samples refer to first institution attended. The NLS72 and NELS:88 samples are restricted to those who attend college within 2 years of cohort high school graduation. Cohort high school graduation is defined as June 1972 for the NLS72 sample and June 1992 for the NELS:88 sample.

b All decompositions are computed using a linear probability model of completion likelihood estimated with the NELS:88 data. Simulated changes are calculated by multiplying the coefficient on a given variable by the observed change in means across surveys.

${ }^{c}$ The Change Due to Observables is the difference between the observed NELS:88 completion rate and the simulated NELS:88 completion rate using the distribution of all observables from NLS72. The changes due to math test percentiles, student-faculty ratios and initial school types are the differences between the observed NELS:88 completion rate and the simulated NELS:88 completion rates in which we simulate the completion rate if the each variable were distributed as in the NLS72 survey and all other observables were unchanged. The Change Due to Supply Side Factors is the sum of the changes due to student-faculty ratios and initial school types. We calculate the Change Due to Student Characteristics as the difference between the Change Due to Observables (X) and the Change Due to Supply-Side Factors. The Change Due to Other Student Characteristics is calculated by subtracting the Change Due to Math Test Percentiles from the Change Due to Student Characteristics.

${ }^{4}$ Data on faculty and enrollment are from the HEGIS/IPEDS surveys from the Department of Education.
} 
Table B-4. Oaxaca-Blinder Decompositions based on NELS:88 Estimates of College Completion by Type of Institution and Gender

\begin{tabular}{|c|c|c|c|c|c|c|}
\hline \multicolumn{7}{|c|}{ Panel A: Men } \\
\hline & $\begin{array}{c}\text { Full } \\
\text { Sample }\end{array}$ & $\begin{array}{c}\text { Public } \\
\text { Non-Top } \\
50 \\
\end{array}$ & $\begin{array}{l}\text { Public } \\
\text { Top } 50 \\
\end{array}$ & $\begin{array}{c}\text { Private } \\
\text { Less } \\
\text { Selective }\end{array}$ & $\begin{array}{c}\text { Private } \\
\text { Highly } \\
\text { Selective }\end{array}$ & $\begin{array}{c}\text { Community } \\
\text { College }\end{array}$ \\
\hline NLS72 & 51.7 & 61.2 & 73.8 & 59.9 & 82.7 & 21.6 \\
\hline NELS:88 & 43.2 & 51.6 & 77.5 & 67.7 & 89.2 & 17.7 \\
\hline Total Change & -8.5 & -9.6 & 3.7 & 7.8 & 6.5 & -3.9 \\
\hline Change Due to Observables (X) & -6.1 & -1.4 & 2.7 & 1.2 & 8.1 & -3.5 \\
\hline Change Due to Student Characteristics & -0.9 & 2.1 & 2.2 & 1.7 & 7.8 & -2.9 \\
\hline Math Test Percentiles & -2.9 & -0.7 & 0.6 & -2.2 & 0.4 & -4.0 \\
\hline Other Student Characteristics & 2.0 & 2.8 & 1.6 & 3.9 & 7.4 & 1.1 \\
\hline Change Due to Supply-Side Factors & -5.2 & -3.5 & 0.5 & -0.5 & 0.3 & -0.6 \\
\hline Student-Faculty Ratios & -1.5 & -3.5 & 0.5 & -0.5 & 0.3 & -0.6 \\
\hline Initial School Types & -3.7 & & & & & \\
\hline Residual & -2.4 & -8.2 & 1.0 & 6.6 & -1.6 & -0.4 \\
\hline
\end{tabular}




\section{Panel B: Women}

\begin{tabular}{|c|c|c|c|c|c|c|}
\hline & $\begin{array}{c}\text { Full } \\
\text { Sample }\end{array}$ & $\begin{array}{c}\text { Public } \\
\text { Non-Top } \\
50 \\
\end{array}$ & $\begin{array}{l}\text { Public } \\
\text { Top } 50 \\
\end{array}$ & $\begin{array}{c}\text { Private } \\
\text { Less } \\
\text { Selective }\end{array}$ & $\begin{array}{c}\text { Private } \\
\text { Highly } \\
\text { Selective }\end{array}$ & $\begin{array}{c}\text { Community } \\
\text { College }\end{array}$ \\
\hline NLS72 & 49.2 & 62.4 & 73.1 & 56.5 & 75.6 & 18.6 \\
\hline NELS:88 & 48.5 & 61.8 & 87.7 & 72.6 & 91.4 & 17.5 \\
\hline Total Change & -0.8 & -0.6 & 14.6 & 15.9 & 15.8 & -1.1 \\
\hline Change Due to Observables (X) & -3.7 & -0.4 & 4.0 & 5.3 & 9.8 & -4.0 \\
\hline Change Due to Student Characteristics & 0.2 & 3.6 & 3.3 & 6.2 & 9.8 & -3.4 \\
\hline Math Test Percentiles & -0.8 & 1.1 & 2.2 & 2.5 & 0.8 & -2.6 \\
\hline Other Student Characteristics & 1.0 & 2.5 & 1.1 & 3.7 & 9.0 & -0.8 \\
\hline Change Due to Supply-Side Factors & -3.9 & -4.0 & 0.7 & -0.9 & 0.0 & -0.6 \\
\hline Student-Faculty Ratios & -1.3 & -4.0 & 0.7 & -0.9 & 0.0 & -0.6 \\
\hline Initial School Types & -2.6 & & & & & \\
\hline Residual & 2.9 & -0.2 & 10.6 & 10.6 & 6.0 & 2.9 \\
\hline
\end{tabular}

\footnotetext{
a Source: Authors' calculations as described in the text from the NLS72 and NELS:88 surveys . NLS72 calculations were made using the fifth follow-up weights included in the survey. Fourth follow-up weights were used for the NELS:88 survey calculations. Only those participating in these follow-ups are included in the regression. School type samples refer to first institution attended. The NLS72 and NELS:88 samples are restricted to those who attend college within 2 years of cohort high school graduation. Cohort high school graduation is defined as June 1972 for the NLS72 sample and June 1992 for the NELS:88 sample.

${ }^{\mathrm{b}}$ All decompositions are computed using a linear probability model of completion likelihood estimated with the NELS:88 data. Simulated changes are calculated by multiplying the coefficient on a given variable by the observed change in means across surveys.

${ }^{c}$ The Change Due to Observables is the difference between the observed NELS:88 completion rate and the simulated NELS:88 completion rate using the distribution of all observables from NLS72. The changes due to math test percentiles, student-faculty ratios and initial school types are the differences between the observed NELS:88 completion rate and the simulated NELS:88 completion rates in which we simulate the completion rate if the each variable were distributed as in the NLS72 survey and all other observables were unchanged. The Change Due to Supply Side Factors is the sum of the changes due to student-faculty ratios and initial school types. We calculate the Change Due to Student Characteristics as the difference between the Change Due to Observables (X) and the Change Due to Supply-Side Factors. The Change Due to Other Student Characteristics is calculated by subtracting the Change Due to Math Test Percentiles from the Change Due to Student Characteristics.

${ }^{\mathrm{d}}$ Data on faculty and enrollment are from the HEGIS/IPEDS surveys from the Department of Education.
} 